\title{
A novel bio-based epoxy resin from oligomer: Excellent processability, high heat resistance, and intrinsic flame retardancy
}

\author{
S. H. Liu, X. Q. Zhang ${ }^{*}$, J. H. Liu, C. H. Lei, Z. X. Dong \\ Guangdong Provincial Key Laboratory of Functional Soft Condensed Matter, School of Materials and Energy, \\ Guangdong University of Technology, No.100 Waihuan West Road, 510006 Guangzhou, China
}

Received 2 June 2021; accepted in revised form 21 July 2021

\begin{abstract}
Preparing an epoxy resin with biomass resources as an alternative for bisphenol A is significant for sustainable and renewable development under great pressure of limited fossil resources and urgent environmental issues. Herein, we synthesized an epoxy oligomer P-DBP-EP-n derived from biomass magnolol through an efficient one-step glycidylation. P-DBP-EP-n exhibited a low viscosity of $11.7 \mathrm{~Pa} \cdot \mathrm{s}$ at room temperature, endowing it with excellent processability as diglycidyl ether of bisphenol A (DGEBA) and magnolol-based epoxy monomer EDBP. Then P-DBP-EP-n was cured with a diamine curing agent, 4,4'-diaminodiphenyl methane (DDM), and following thermal addition polymerization of allyl units. Compared with DGEBA/DDM and EDBP/DDM, P-DBP-EP-n/DDM possessed a higher glass transition temperature $\left(T_{\mathrm{g}}\right)$ (304 to 167 and $226^{\circ} \mathrm{C}$ ), implying distinguished heat resistance. Furthermore, the tensile properties and notched impacted strength of P-DBP-EP-n/DDM were better than EDBP/DDM (20.7 to $19.4 \mathrm{MPa}, 2.0$ to $1.6 \mathrm{GPa}$, and 2.5 to $2.0 \mathrm{~kJ} / \mathrm{m}^{2}$ ). The initial degradation temperature and char residue of P-DBP-EP-n/DDM were $421{ }^{\circ} \mathrm{C}$ and $35.2 \%$, with a 13.5 and $101 \%$ increase compared with those of DGEBA/DDM, respectively. Additionally, P-DBP-EP-n/DDM displayed outstanding flame retardancy with V-0 rate for the vertical burning test and limiting oxygen index value of $47.7 \%$, which was almost twice as much as that of DGEBA/DDM. This study offers a promising and feasible pathway to obtain a fully bio-based epoxy resin substituted for petroleum-based DGEBA with distinguished processability, heat resistance, and flame retardancy. Comprehensive properties of the bio-based thermosets are expected to be further regulated by the thermal addition polymerization of allyl units.
\end{abstract}

Keywords: thermal properties, biomass, oligomer, low viscosity, intrinsic flame retardancy

\section{Introduction}

Epoxy resin, an important thermoset, is extensively used in constructions, composites, electrical engineering, and electronics for its high corrosive resistance, low curing shrinkage, and excellent mechanical, thermal, and electrical properties. Currently, petroleum-based DGEBA which originates from bisphenol A (BPA) and epichlorohydrin takes up dominance [1]. Not only is BPA strongly dependent on the chemical industry, but it also acts as an endocrine disruptor [2] due to the similar structure to estrogens. It is harmful to human immune and reproductive systems because BPA and its derivatives will leach from plastic packaging [3]. In terms of the negative impact of BPA on humans, some countries and organizations such as Canada and the EU have banned BPA as raw materials for food packaging products, especially infant bottles [4]. Therefore, with the concern of accelerating consumption of fossil fuel and increasing awareness of the health of humans, it is necessary to find biomass to replace BPA to prepare epoxy resins. 
With a large stock and wide range of sources, renewable biomass has attracted increasing attention in designing bio-based epoxy resins [1, 3, 5-7]. It has been reported that biomass like soybean oil [8], tung oil [9], linseed oil [10] and cardanol [11] can be easily epoxidized to obtain corresponding epoxy resins. They generate extremely low viscosity $[9,12,13]$ at room temperature due to strong chain mobility from the long flexible aliphatic chains. However, such a long flexible aliphatic chain always results in relatively low Tg compared with conventional BPA-based one [14]. Consequently, the epoxies mentioned above tend to be used for diluting viscous systems and toughening brittle system $[12,15,16]$ rather than be used alone where high-performance is required.

In terms of drawbacks arising from the aliphatic chain, the introduction of rigid and aromatic structures is expected to improve the $T_{\mathrm{g}}$ of the bio-based resins $[3,17,18]$. Renewable materials such as lignin [19], vanillin [20, 21], and eugenol [22, 23] have attracted much attention for their fascinating aromatic structures and high reactivity from phenolic hydroxyl groups. For example, Wan et al. [4] synthesized a novel epoxy based on eugenol with a rigid core of cyanuric chloride. The $T_{\mathrm{g}}$ of the resin cured by 3,3'DDS was $207^{\circ} \mathrm{C}, 18.9 \%$ higher than that of the DGEBA-based one. Moreover, Tian et al. [24] demonstrated that $T_{\mathrm{g}}$ also had a close tie with the crosslinking density of the cured network. The cured trifunctional resveratrol-based epoxy resin with a high crosslinking density of $6900.6 \mathrm{~mol} / \mathrm{m}^{3}$ (DGEBA $2087.4 \mathrm{~mol} / \mathrm{m}^{3}$ ) possessed a corresponding high $T_{\mathrm{g}}$ of $210.8{ }^{\circ} \mathrm{C}$, with a $39 \%$ increase compared with DGEBA-based. However, the above bio-based epoxies always yield powder even crystal [3] at room temperature owing to the rigid aromatic backbone and the accompanying poor chain mobility. Hence, they need to be melted under high temperature or diluted with solvent before molding. But it is difficult to remove all the solvent during degassing process and the remaining solvent will influence the performance of the final product.

Magnolol, which is extracted from biomass magnolia officinalis and confirmed safe and low toxicity [25], is widely used in herbs and make-up for its unique anti-bacterial, anti-tumor effect. It contains symmetrical and reactive allyl groups and phenolic hydroxyl groups. Hence, it is easy to be modified, obtaining bio-based derivatives [26] and thermosets with excellent thermal properties [27]. It has been reported that the introduction of allyl groups can improve processability, using in various epoxy systems $[28,29]$. The symmetrical biphenyl structures not only enhance the thermal stability but also promote char formation during combustion, therefore possessing intrinsic flame retardancy [30]. A previous study has demonstrated that magnolol-based epoxy monomer DGEM exhibited better thermal properties compared with DGEBA-based ones whereas tensile and impact properties were still mysterious [31]. Furthermore, DGEM was an epoxy monomer, which was quite different from most of the commercial epoxy resins with a series of degrees of polymerization. The properties of epoxy oligomers can be controlled by regulating the degree of polymerization [32]. Unfortunately, there are few relative reports, and the properties of resulting epoxy oligomers could not compete with the DGEBA-based one, especially $T_{\mathrm{g}}$ values [33, 34].

The increasing focus on bio-based epoxy resins has motivated us to design an inherent fascinating molecular structure, achieving balanced performances. In this study, we designed and synthesized a biobased glycidyl ether oligomer (P-DBP-EP-n) using biomass magnolol and epichlorohydrin through a one-step glycidylation reaction. It is desirable to address the contradiction between processability and thermal properties with the combination of flexible allyl groups and rigid biphenyl structures of magnolol moieties. Oligomer P-DBP-EP-n was cured with the diamine curing agent DDM and following thermal addition polymerization. Tensile and notched impact properties were determined. Dynamic mechanical analysis (DMA), thermogravimetric analysis (TGA), vertical burning test (UL94), and limiting oxygen index (LOI) were carried out to investigate the thermal and flame-retardant properties of the thermosets P-DBP-EP-n/DDM. To further ascertain the mechanism of intrinsic flame retardancy, scanning electron microscopy (SEM) was used to observe the morphology of the residual char collected from flame retardancy tests. It will be a promising and feasible method to synthesize a bio-based epoxy oligomer as a BPA-free substitute for DGEBA for a wider application.

\section{Experimental section}

\subsection{Materials}

Magnolol was purchased from Guangzhou Seye Biological Technology Co., Ltd (Guangzhou, China). 
DGEBA (epoxy value $=0.48 \sim 0.54 \mathrm{~mol} / 100 \mathrm{~g}$ ) was provided from Hangzhou Wuhuigang Adhesive (Hangzhou, China). Epichlorohydrin (ECH), tetrabutylammonium bromide (TBAB), tetraethylammonium bromide (TEAB), 4,4-diaminodiphenyl methane (DDM), crystal violet, and perchloric acid (0.1 $\mathrm{M}$ in glacial acetic) were obtained from Sigma-Aldrich. Analytical ethyl acetate and glacial acetic acid, sodium hydroxide $(\mathrm{NaOH})$, sodium chloride $(\mathrm{NaCl})$, and anhydrous magnesium sulfate $\left(\mathrm{MgSO}_{4}\right)$ were supplied from Tianjin Zhiyuan Chemical Reagent Co., Ltd (Tianjin, China). All the reagents were used as received without any further purification.

\subsection{Synthesis of magnolol-based epoxy oligomer (P-DBP-EP-n)}

Magnolol (5 g, $18.7 \mathrm{mmol})$, ECH (6.9 g, $74.8 \mathrm{mmol}$ ), and TBAB $(0.06 \mathrm{~g}, 0.5 \mathrm{wt} \%)$ were added into a threenecked round-bottomed flask, which was equipped with a mechanical stirring bar and reflux unit. The mixture was continuously and homogeneously stirred at $50^{\circ} \mathrm{C}$ for $2 \mathrm{~h}$. An aqueous solution of $\mathrm{NaOH}$ (40 wt $\%, 5 \mathrm{ml}$ ) was added dropwise using a constant flow pump to the mixture. Afterward, the mixture further reacted for another $3 \mathrm{~h}$ with vigorous stirring at $80^{\circ} \mathrm{C}$. Subsequently, excess ethyl acetate was added to dilute the mixture and then washed three times with distilled water and once with saturated $\mathrm{NaCl}$ solution. Then the organic phase was dried with anhydrous $\mathrm{MgSO}_{4}$ overnight. After that, the organic phase was concentrated under vacuum to remove excess $\mathrm{ECH}$ and ethyl acetate and further dried at $50^{\circ} \mathrm{C}$ in a vacuum oven to yield the target product P-DBPEP-n as a pale yellow liquid.

\subsection{Synthesis of magnolol-based monomer (EDBP)}

Magnolol (5 g), ECH (17.3 g, 5 eq.), and TBAB ( $0.6 \mathrm{~g}, 0.05$ eq.) were charged into a three-necked round-bottomed flask, which was equipped with a magnetic stirring bar and reflux unit. The mixture was allowed to be stirred at $80^{\circ} \mathrm{C}$ for $3 \mathrm{~h}$. Subsequently, $\mathrm{NaOH}$ ( 3 g, 2 eq) and $\mathrm{TBAB}$ ( $0.6 \mathrm{~g}, 0.05$ eq.) was added into $15 \mathrm{ml}$ of distilled water, and the solution was added into the mixture. Then the mixture reacted for another hour at room temperature with stirring. After that, ethyl acetate was used to dilute the mixture and then rinsed three times with distilled water and once with saturated $\mathrm{NaCl}$ solution. The organic phase was dried with anhydrous $\mathrm{MgSO}_{4}$ overnight. Next, the organic phase was concentrated under vacuum to remove excess ECH and ethyl acetate and further dried at $50^{\circ} \mathrm{C}$ in a vacuum oven to yield the final product EDBP as a light yellow liquid.

\subsection{Thermal curing of P-DBP-EP-n and EDBP}

The curing agent DDM was employed in this work to obtain cured epoxy resins, taking P-DBP-EP-n as an example. Firstly, DDM was added into P-DBPEP-n with a molar ratio of epoxy groups to $\mathrm{N}-\mathrm{H}$ as $1: 1$. The mixture was stirred vigorously at $90^{\circ} \mathrm{C}$ until DDM completely dissolved. Subsequently, the mixture was degassed in a vacuum oven at $50{ }^{\circ} \mathrm{C}$ to remove trapped air and then poured into a silica gel mold. The curing behavior was monitored by differential scanning calorimetry (DSC) and Fourier Transform Infrared (FTIR). According to results of DSC and FTIR (discussed in Curing network of P-DBPEP-n/DDM Section), the sample was cured at $100^{\circ} \mathrm{C}$ for $1 \mathrm{~h}, 140^{\circ} \mathrm{C}$ for $1 \mathrm{~h}, 180^{\circ} \mathrm{C}$ for $2 \mathrm{~h}$ in the oven, and $320^{\circ} \mathrm{C}$ for $8 \mathrm{~h}$ in a tube furnace to get a completely cured resin, denoted as P-DBP-EP-n/DDM. For comparison, DGEBA/DDM and EDBP/DDM were cured with a similar procedure, respectively.

\subsection{Characterization}

${ }^{1} \mathrm{H}$ nuclear magnetic resonance ( ${ }^{1} \mathrm{H}$ NMR) spectra were recorded on a Bruker 400 (Switzerland) nuclear magnetic resonance spectrometer. Matrix-assisted laser desorption/ionization time-of-flight mass spectrometry (MALDI-TOF) was performed on a Bruker Ultraflextreme MALDI-TOF (Germany) with a positive ion mode

The epoxy value of the epoxy oligomer was titrated according to ASTM D1652. $0.4 \mathrm{~g}$ epoxy oligomer was dissolved in $10 \mathrm{ml}$ of methylene chloride, and then $10 \mathrm{ml}$ of tetraethylammonium bromide in glacial acetic acid solution $(250 \mathrm{mg} / \mathrm{ml})$ and $6 \sim 8$ drops of $0.1 \%$ crystal violet indicator in glacial acetic acid solution were added. The mixed solution was titrated to a green color with $0.1 \mathrm{M}$ perchloric acid in glacial acetic acid solution.

The epoxy-amine reaction was monitored by DSC (METTLER TOLEDO DSC 3, Switzerland) with a heating rate of $10^{\circ} \mathrm{C} / \mathrm{min}$ ranging from 25 to $370^{\circ} \mathrm{C}$ under $50 \mathrm{ml} / \mathrm{min}$ nitrogen gas flow. The polymerization of allyl units was determined by FTIR using a Nicolet IS-50 FTIR spectrometer (Thermo Fisher Scientific, USA) with the wavenumber range of 
$4000-500 \mathrm{~cm}^{-1}$. All the samples were mixed with $\mathrm{KBr}$ pellets to press into small flakes, and the area of the characteristic peaks was integrated using the Origin 8.5 software package. The degassed mixture was cured in Jinghong XMTD-8222 (China) oven first and then a tube furnace (GSL-1400X, Hefei Kejing Technology Co., Ltd, China.).

Viscosity was investigated using an Anton Paar Modular Compact Rheometer (Austria) as a function of shear rate from 1 to $100 \mathrm{l} / \mathrm{s}$ and temperature from 25 to $40^{\circ} \mathrm{C}$ fitted with $25 \mathrm{~mm}$-cone parallel plates, respectively. A separation of $0.051 \mathrm{~mm}$ between the plates was used for all the samples. Dynamic mechanical analysis (DMA) was performed using an Anton Paar Modular Compact Rheometer (Austria) under torsional mode with a constant frequency of $1 \mathrm{~Hz}$, amplitude of $0.1 \%$, and a heating rate of $5^{\circ} \mathrm{C} / \mathrm{min}$. Thermal gravimetric analysis (TGA) was conducted on a NETZSCH STA449F5 (Germany) thermogravimetric analyzer with a temperature range from 30 to $700^{\circ} \mathrm{C}$ and a heating rate of $10^{\circ} \mathrm{C} / \mathrm{min}$ under $40 \mathrm{ml} / \mathrm{min}$ nitrogen gas flow.

Tensile properties of the cured epoxy resins were determined by Gotech testing machines inc.AI-7000M micro-tensile tester (China). The measurements were performed on standardized dog-bone samples at a speed of $1 \mathrm{~mm} / \mathrm{min}$ according to GB/T 1040-92. The notched impact properties of the cured epoxy resins were investigated using Guangce Automation Digital IZOD impact tester (China) according to GB/T 1843-2008.

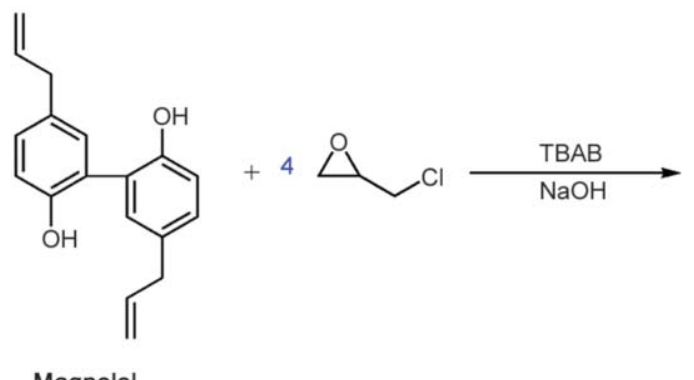

Magnolol

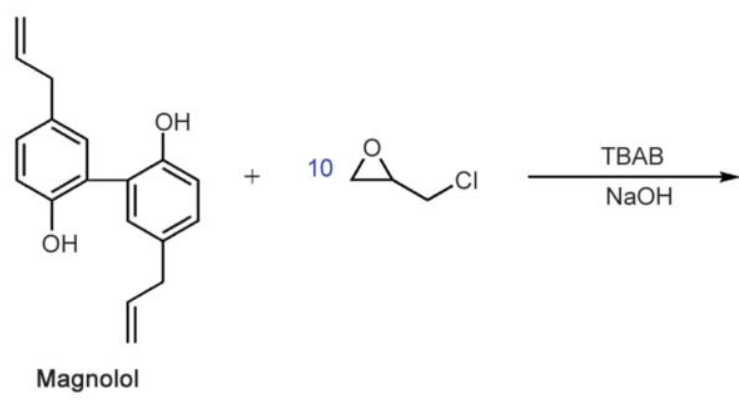

Limiting oxygen index (LOI) values were characterized by a PDF-60B oxygen index meter (Shandong Derek Instruments Co., Ltd., China) according to ASTM D 2863-97 with the specimen measured $130 \mathrm{~mm} \times 6.5 \mathrm{~mm} \times 3 \mathrm{~mm}$. Vertical burning tests (UL94) were conducted on a ZCF-5 horizontal and vertical instrument (Nanjing Jionglei Instrument Equipment Co., Ltd., China) according to ASTM D 3801 with the samples measured $130 \mathrm{~mm} \times 13 \mathrm{~mm} \times$ $3.2 \mathrm{~mm}$.

The morphology of the residual char was observed using scanning electron microscopy (SEM) on a Hitachi S-3400 N-II scanning electron microscope (Japan) with the accelerating voltage of $15 \mathrm{kV}$.

\section{Results and discussion \\ 3.1. Synthesis of P-DBP-EP-n}

As shown in Figure 1, P-DBP-EP-n was synthesized through a one-step glycidylation reaction using magnolol, excess ECH, and a small amount of phase transfer initiator TBAB under alkaline conditions. Excessive ECH is always employed in glycidylation reaction, which can minimize the formation of higher molecular oligomers, obtaining monomers or low molecular oligomers. The average chain length can be controlled by varying the excess of ECH. In the current study, 4 and 10 times ECH were applied for the preparation of oligomer P-DBP-EP-n and monomer EDBP, respectively. The chemical structure of P-DBP-EP-n and EDBP was confirmed by ${ }^{1} \mathrm{H}$ NMR (Figure 2a, 2c) and ${ }^{13} \mathrm{C}$ NMR (Figure 2b, 2d). In

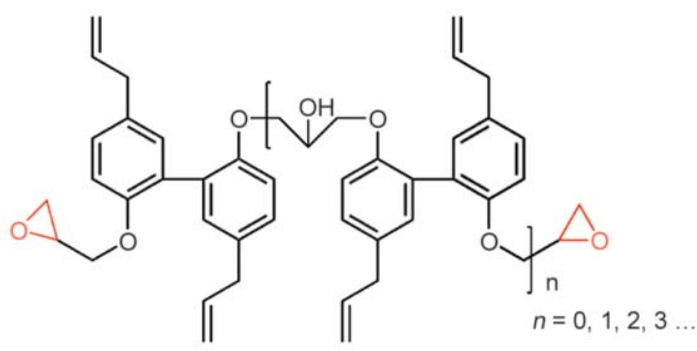
P-DBP-EP-n

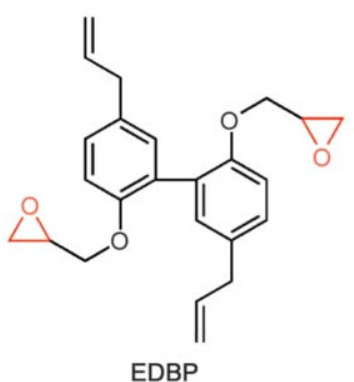

Figure 1. The synthetic route of P-DBP-EP-n and EDBP from magnolol. 

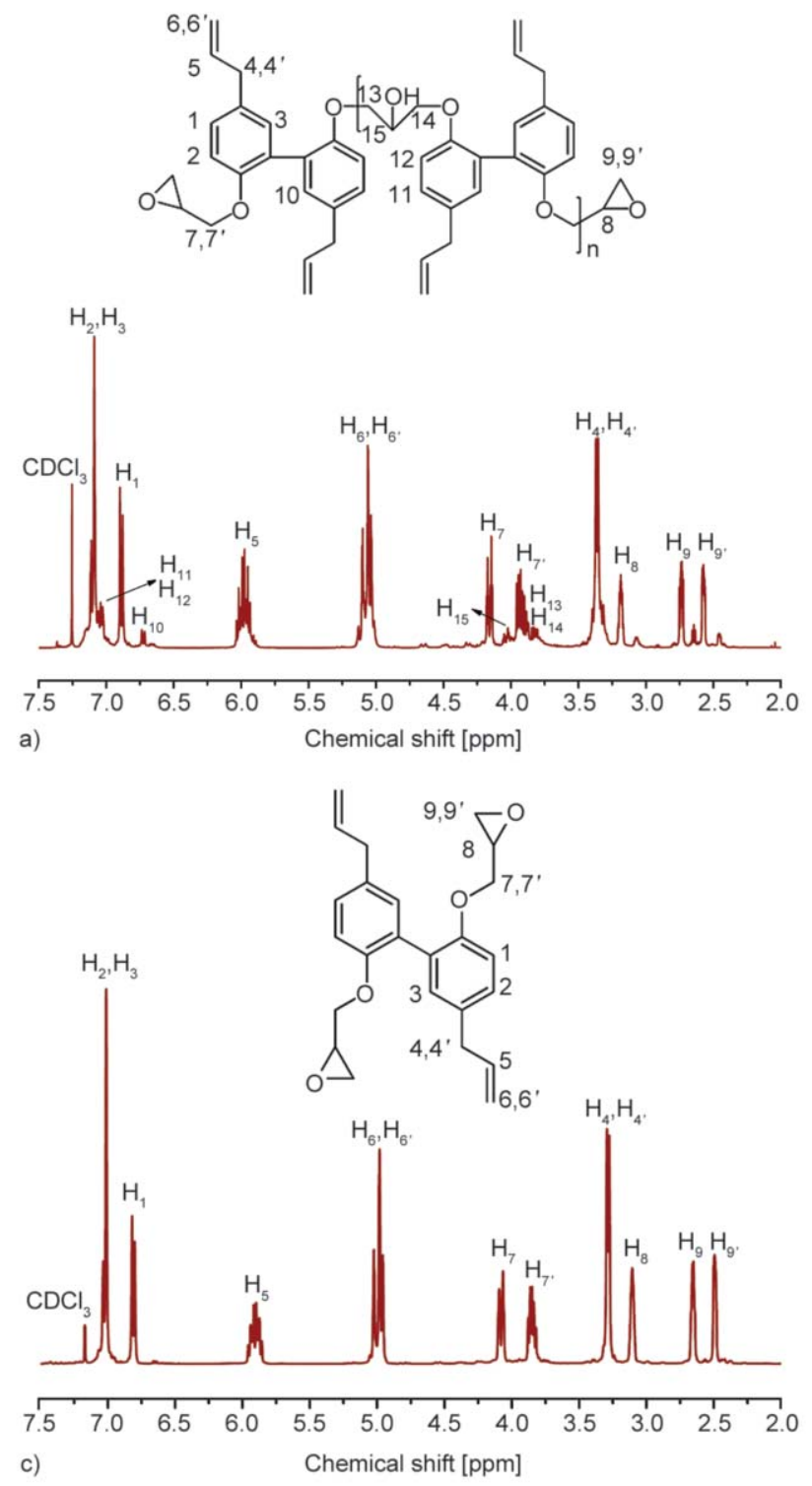

Figure 2. The ${ }^{1} \mathrm{H}$ NMR spectrum of a) P-DBP-EP-n, c) EDBP, and ${ }^{13} \mathrm{C}$ NMR spectrum of b) P-DBP-EP-n, d) EDBP.

Figure 2a, chemical shifts of $5.06\left(\mathrm{H}_{6}, \mathrm{H}_{6^{\prime}}\right)$ and 5.98 $\left(\mathrm{H}_{5}\right)$ ppm were ascribed to the allyl groups of magnolol, and $3.19\left(\mathrm{H}_{8}\right), 2.73\left(\mathrm{H}_{9}\right)$, and $2.57\left(\mathrm{H}_{9^{\prime}}\right) \mathrm{ppm}$ were attributed to epoxy rings. Both of the chemical shifts of ${ }^{1} \mathrm{H}$ NMR and ${ }^{13} \mathrm{C}$ NMR were consistent with the statement in the literature [31]. Interestingly, compared with monomer EDBP (Figure 2d), a new chemical shift at $\sim 69 \mathrm{ppm}$, which was ascribed to $\mathrm{C}_{13}, \mathrm{C}_{14}$, and $\mathrm{C}_{15}$ was observed in ${ }^{13} \mathrm{C}$ NMR spectrum (Figure 2b), indicating the successful synthesis of P-DBP-EP-n. Additionally, the average repeating unit of P-DBP-EP-n was characterized by ${ }^{1} \mathrm{H}$ NMR, comparing allyl groups integrations $(3(2 n+2) \mathrm{H}$ per molecule, 3.05) with epoxide groups integrations $(6 \mathrm{H})$ per molecule, 1.65) [32]. The ratio was 1.84 , implying that the average polymerization degree $(n)$

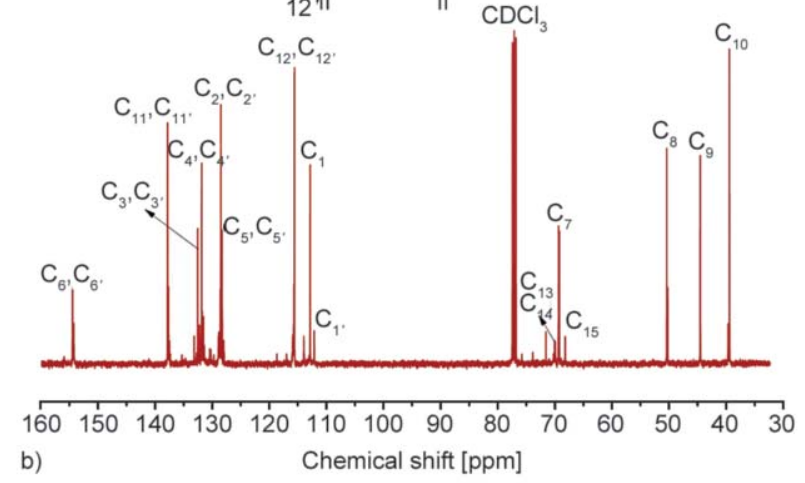<smiles>[Y1]=COc1ccc(OC[C@H]2CO2)c(-c2cc(CC=C)ccc2OCC2CO2)c1</smiles>

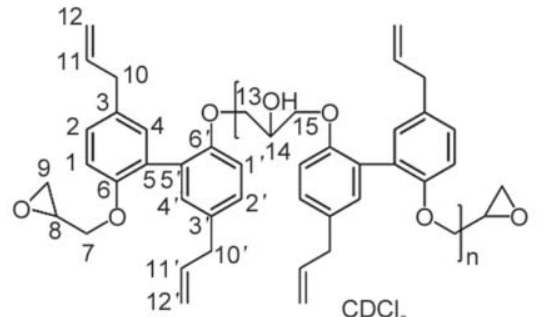

was 0.92. To further determine the composition of the oligomer P-DBP-EP-n, MALDI-TOF was carried out, and the results are listed in Table 1. As shown in Figure 3, the strongest signal peak at $723.412 \mathrm{~m} / \mathrm{z}$ was observed, which was corresponding to P-DBPEP-n with a polymerization degree of 1 . From data of Table 1, P-DBP-EP-n was a mixture of magnololbased epoxy with different $n$ values ranging from

Table 1. The MALDI-TOF Mass results of P-DBP-EP-n.

\begin{tabular}{|c|c|c|c|}
\hline $\begin{array}{c}\text { Degree of } \\
\text { polymerization, } \boldsymbol{n}\end{array}$ & Calculated $\left[\mathbf{M}+\mathbf{N a}^{+}\right]$ & {$\left[\mathbf{M}+\mathbf{N a}^{+}\right]$} & $\begin{array}{c}\text { Percent } \\
{[\mathbf{\%}]}\end{array}$ \\
\hline 0 & 401.46 & 401.12 & 11.6 \\
\hline 1 & 723.86 & 723.41 & 47.3 \\
\hline 2 & 1046.27 & 1045.62 & 27.8 \\
\hline 3 & 1368.67 & 1367.85 & 9.6 \\
\hline 4 & 1689.10 & 1690.10 & 3.6 \\
\hline
\end{tabular}




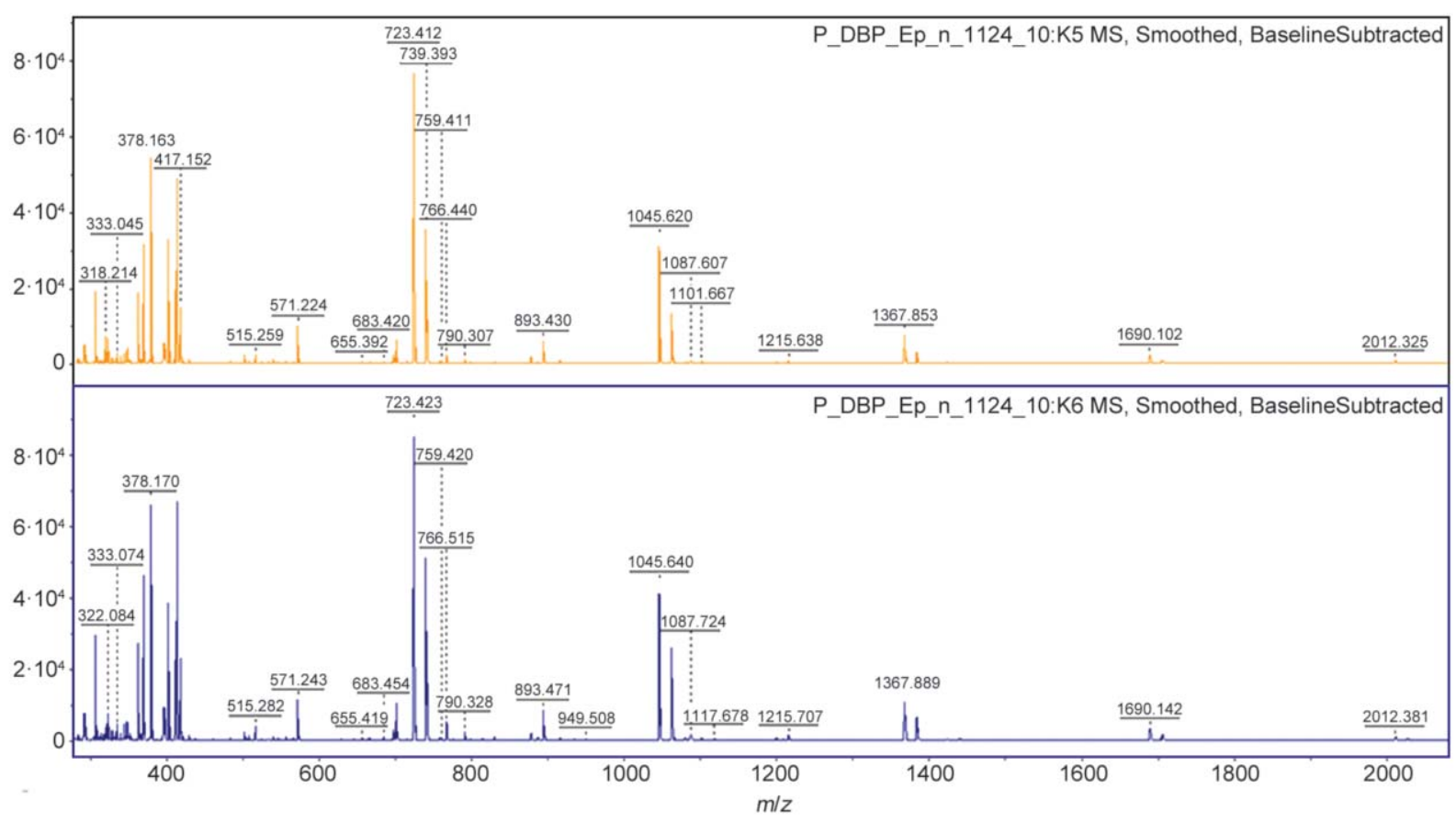

Figure 3. The MALDI-TOF spectrum of P-DBP-EP-n.

0 to 4 , in which $n=1$ came into prominence, accounting for $47.3 \%$. Components with polymerization of $n=0,2,3$ and 4 took up 11.6, 27.8, 9.6 and $3.6 \%$ respectively. Furthermore, the epoxy value of the oligomer P-DBP-EP-n was titrated to be 0.31 mol/100 g according to ASTM D1652. All the results above indicate that the magnolol-based oligomer was successfully synthesized, and the average polymerization degree was approximately 1 .

\subsection{Processability of P-DBP-EP-n}

With numerous rigid and compact aromatic structures and accompanying low chain mobility, aromatic bio-based epoxies tend to yield powder with high

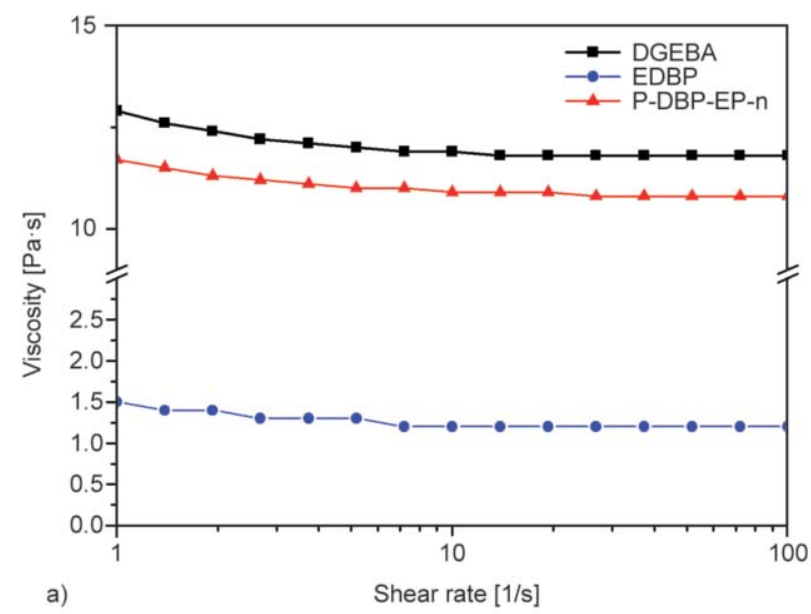

melting points $[3,22]$, which need to be melted before molding. However, P-DBP-EP-n was a liquid at room temperature, which was totally different from most of the aromatic bio-based epoxy resins. In order to characterize the processability of P-DBP-EP-n, a viscosity test was carried out, and results are shown in Figure 4. As shown in Figure 4a, all the epoxies acted as Newtonian fluids with a constant viscosity of 11.7, 12.9, and 1.5 Pa.s for P-DBP-EP-n, DGEBA, and EDBP, respectively. It is noteworthy that the viscosity of P-DBP-EP-n was slightly lower than that of DGEBA, resulting in excellent processability at room temperature. The reason why P-DBP-EP-n exhibited a relatively low viscosity was that aliphatic

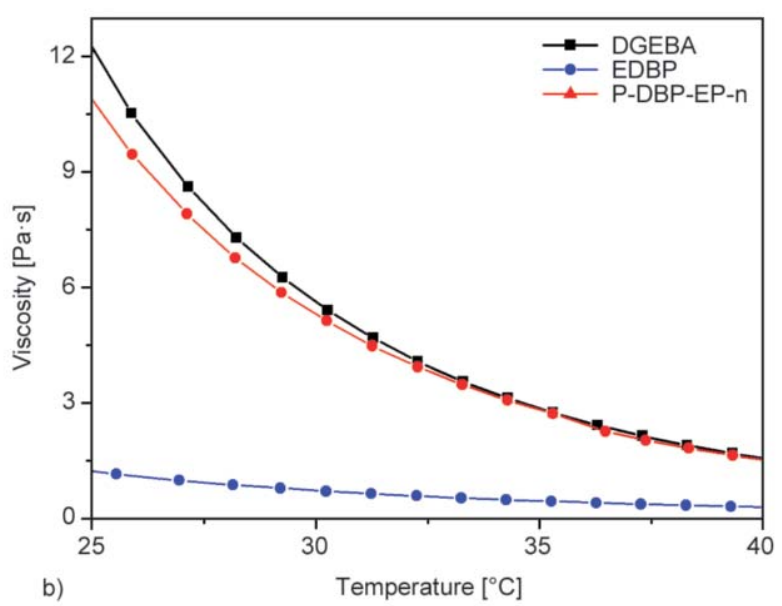

Figure 4. The viscosities of DGEBA, EDBP and P-DBP-EP-n. a) Viscosity as a function of shear rate from 1 to 100 1/s at $25^{\circ} \mathrm{C}$ for DGEBA, EDBP and P-DBP-EP-n without curing agents. b) Viscosity as a function of temperature from 25 to $40^{\circ} \mathrm{C}$ for DGEBA, EDBP and P-DBP-EP-n without curing agents. 
allyl groups increase chain mobility, which is widely used for reducing the viscosity of polymer systems and broadening process window [28, 29]. Rich, flexible allyl units promoted chain motion, improving the free volume and reducing the high aromaticity and rigidity arising from the compact backbone of biphenyl. Moreover, the epoxy needs to be mixed with the curing agent before molding, so we determined the viscosities under variable temperatures with a steady shear rate of $501 / \mathrm{s}$, and the results are shown in Figure $4 \mathrm{~b}$. It was discovered that the viscosities of both DGEBA and P-DBP-EP-n reduced with increasing temperature and ultimately reached $\sim 1 \mathrm{~Pa} \cdot \mathrm{s}$ at $40^{\circ} \mathrm{C}$, which was closed to that of monomer EDBP. From the results collected from the rotational rheology approach, we conclude that P-DBPEP-n exhibits excellent processability, meeting the target of the following molding procedure.

\subsection{Curing network of P-DBP-EP-n/DDM}

The oligomer P-DBP-EP-n has two types of reactive groups and can react under suitable conditions at different temperature ranges, forming distinct crosslinked polymer networks. Figure 5 shows the curing route of P-DBP-EP-n and the probable crosslinked structure of P-DBP- EP-n/DDM. Firstly, epoxy rings of P-DBP-EP-n reacted with amino groups of DDM, opening epoxy rings and obtaining the first cured network, and the resulting thermoset was denoted as P-DBP-EP-n/DDM-180. Secondly, thermal addition polymerization of allyl groups was triggered at higher temperatures [35], forming the second cured network as illustrated in Figure $5 b$.

To confirm the suitable curing process, DSC and FTIR were carried out to monitor the epoxy-amine reaction and thermal addition polymerization of allyl units, respectively. A broad exothermic peak from $\sim 80$ to $\sim 275^{\circ} \mathrm{C}$, with a temperature of exothermal peak $\left(T_{\mathrm{p}}\right)$ of $\sim 150^{\circ} \mathrm{C}$ was observed in the DSC curve, which was corresponding to the epoxy-amine reaction. It is suggested that epoxies started to react with amines at $\sim 80^{\circ} \mathrm{C}$ and the fastest reaction occurred at $\sim 150^{\circ} \mathrm{C}$. According to reports, a higher temperature could trigger thermal addition polymerization [35], but unfortunately, DSC failed to determine the reaction within a limited experimental time. Therefore, FTIR was carried out to investigate the optimum curing temperature using a series of cured resins with different second curing temperatures (denoted as P-DBP-EP-n/DDM-T). As we all know, characteristic peaks of allyl groups appear at $\sim 1637, \sim 995$, and $\sim 914 \mathrm{~cm}^{-1}$, which can be used as a symbol of the extent of thermal addition polymerization. In this study, the characteristic peak at $911 \mathrm{~cm}^{-1}$ was chosen as an index, and its area integration was used to estimate whether allyl groups reacted completely during the second curing procedure. Detailed results are listed in Table 2. For comparison, EDBP/DDM was prepared with a similar curing procedure, and the FTIR spectra are shown in Figure 6b. As for P-DBP-EP$\mathrm{n} / \mathrm{DDM}$, it was observed that the intensities of characteristic peaks of allyl groups were gradually weaker and finally disappeared with increasing second curing temperature, as shown in Figure 6a. From data in Table 2, it was found that the ratio of the integrated area of peaks at $911 \mathrm{~cm}^{-1}$ decreased vastly after $280^{\circ} \mathrm{C}$, indicating that thermal addition polymerization accelerated over $280^{\circ} \mathrm{C}$ and gradually got completed at higher curing temperature and ultimately finished at $320^{\circ} \mathrm{C}$. Hence, the whole curing

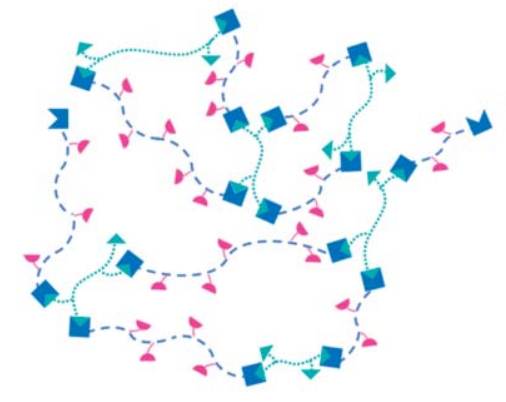

a) Epoxy-amine curing network

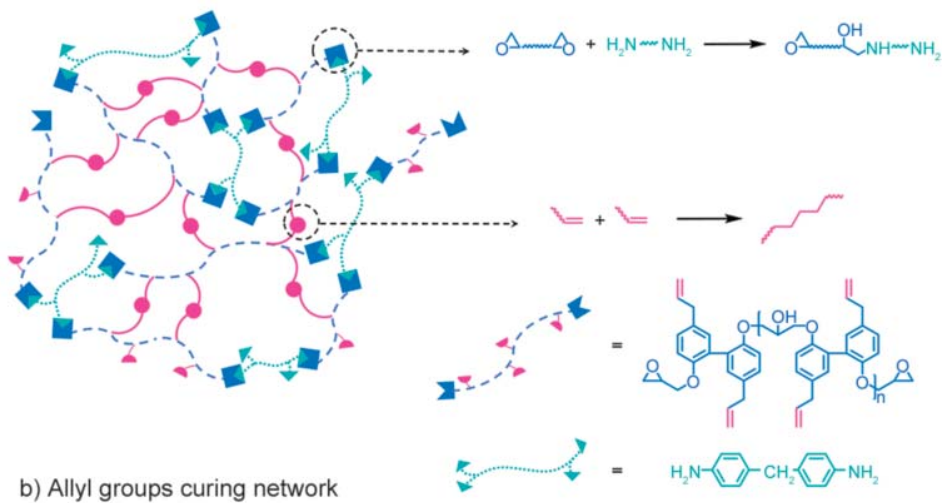

b) Allyl groups curing network
Thermal addition of allyl group

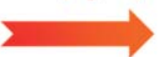

Figure 5. The curing route of P-DBP-EP-n with DDM and the probable crosslinked structure of the cured resins. a) Epoxy rings opening reaction and the probable crosslinked structure for P-DBP-EP-n-180. b) Allyl groups thermal addition polymerization reaction and the probable crosslinked structure for P-DBP-EP-n/DDM-320. 

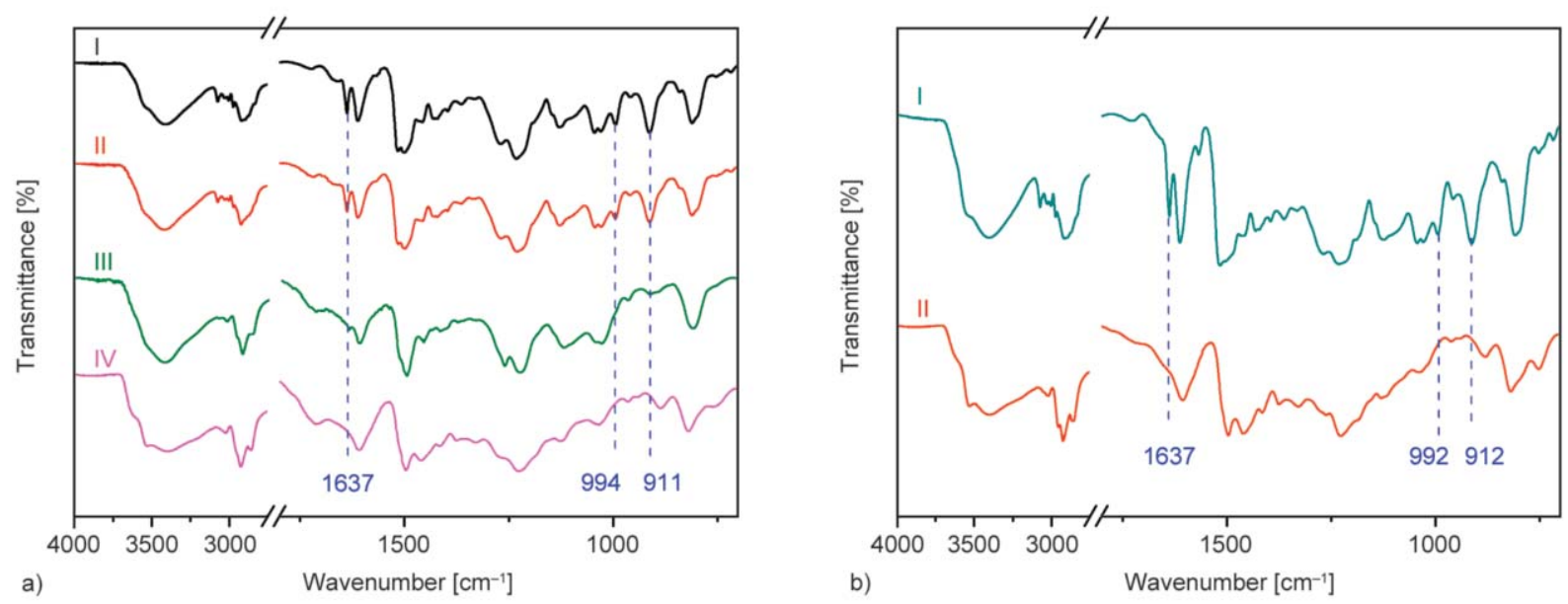

Figure 6. The FTIR spectra of samples with different second curing process. a) P-DBP-EP-n/DDM, I) P-DBP-EP-n/DDM180, II) P-DBP-EP-n/DDM-280, III) P-DBP-EP-n/DDM-300, IV) P-DBP-EP-n/DDM-320. b) EDBP/DDM, I) EDBP/DDM-180, II) EDBP/DDM-290.

Table 2. Integration of characteristic peak in FTIR spectra for cured resins P-DBP-EP-n/DDM with different second curing process.

\begin{tabular}{|l|c|c|}
\hline & Area of peak at $\mathbf{9 1 2} \mathbf{~ c m}^{-\mathbf{1}}$ & $\boldsymbol{A}_{\mathbf{T}} / \boldsymbol{A}_{\mathbf{1 8 0}}{ }^{*}$ \\
\hline P-DBP-EP-n/DDM-180 & 1259 & 1.00 \\
\hline P-DBP-EP-n/DDM-280 & 1004 & 0.80 \\
\hline P-DBP-EP-n/DDM-300 & 156 & 0.12 \\
\hline P-DBP-EP-n/DDM-320 & - & - \\
\hline
\end{tabular}

${ }^{*} T$ represents $180,280,300$ and 320 , respectively.

process was confirmed as follows: $100^{\circ} \mathrm{C} 1 \mathrm{~h}, 140^{\circ} \mathrm{C}$ $1 \mathrm{~h}, 180^{\circ} \mathrm{C} 2 \mathrm{~h}$ in the oven, and $320^{\circ} \mathrm{C} 8 \mathrm{~h}$ in a furnace. The obtained dual-cured network with a high crosslinking density might endow the cured resin with a high $T_{\mathrm{g}}$.

\subsection{Thermomechanical properties of cured P-DBP-EP-n/DDM}

To further confirm our hypothesis, DMA was carried out to evaluate the thermomechanical properties of the cured resins, and the results are shown in Figure 7. As could be seen in Figure 7a, storage modulus increased from 5295.8 MPa (P-DBP-EP-n/DDM180) to $9413.7 \mathrm{MPa}$ (P-DBP-EP-n/DDM-320), with a tremendous increase of $77.8 \%$. As we discussed above, P-DBP-EP-n/DDM-180 only conducted an epoxy ring-opening reaction at $180^{\circ} \mathrm{C}$, indicating that the cured network was not completed yet. However, higher curing temperature promoted thermal addition polymerization of allyl groups which provided extra crosslinking sites [36], thereby significantly improving the storage modulus of P-DBP-EP-n/DDM320, close to that of DGEBA/DDM (10494 MPa). Remarkably, it was observed that the storage modulus of DGEBA/DDM decreased sharply from $7713 \mathrm{MPa}\left(\sim 134^{\circ} \mathrm{C}\right)$ to $198 \mathrm{MPa}\left(\sim 175^{\circ} \mathrm{C}\right)$, whereas P-DBP-EP-n/DDM-320 remained a storage modulus higher than $6000 \mathrm{MPa}$ before $200^{\circ} \mathrm{C}$. It was suggested that multiple compact biphenyl structures in P-DBP-EP-n/DDM-320 had an advantage in resisting heat and deformation compared with bisphenol A, which can be qualified for application where high temperature is required. As we know, $T_{\mathrm{g}}$ value has a close tie with the crosslink density of the cured resins, and the higher the crosslinking density is, the higher the $T_{\mathrm{g}}$ is $[37,38]$. Distinct $T_{\mathrm{g}}$ values were observed for epoxy systems (Figure 7b), suggesting that they exhibited different crosslinked polymer networks. In order to estimate the influence of crosslinking density on $T_{\mathrm{g}}$, the average molecular weight between crosslinking points $\left(M_{\mathrm{c}}\right)$ of different epoxy systems was calculated according to the Equation (1) and (2) $[37,39]$ :

$M_{\mathrm{c}}=\frac{n_{\mathrm{EP}} M_{\mathrm{EP}}+n_{\mathrm{DDM}} M_{\mathrm{DDM}}}{n_{\mathrm{DDM}}}$

$$
M_{\mathrm{c}}=\frac{n_{\text {reacted allyl groups }} M_{\text {reacted allyl groups }}+n_{\mathrm{EP}} M_{\mathrm{EP}}+n_{\mathrm{DDM}} M_{\mathrm{DDM}}}{n_{\text {reacted allyl groups }}+n_{\mathrm{DDM}}}
$$



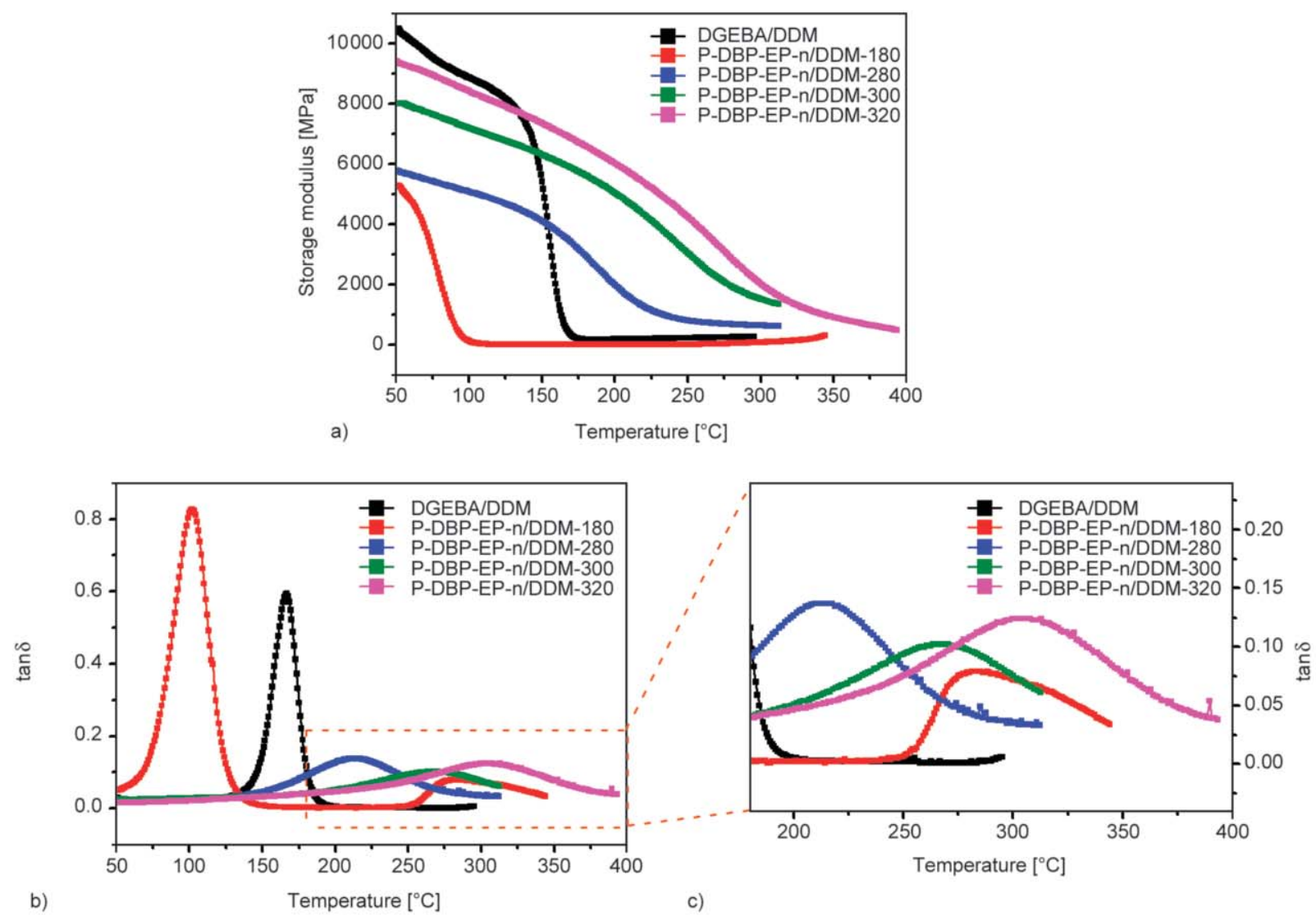

c)
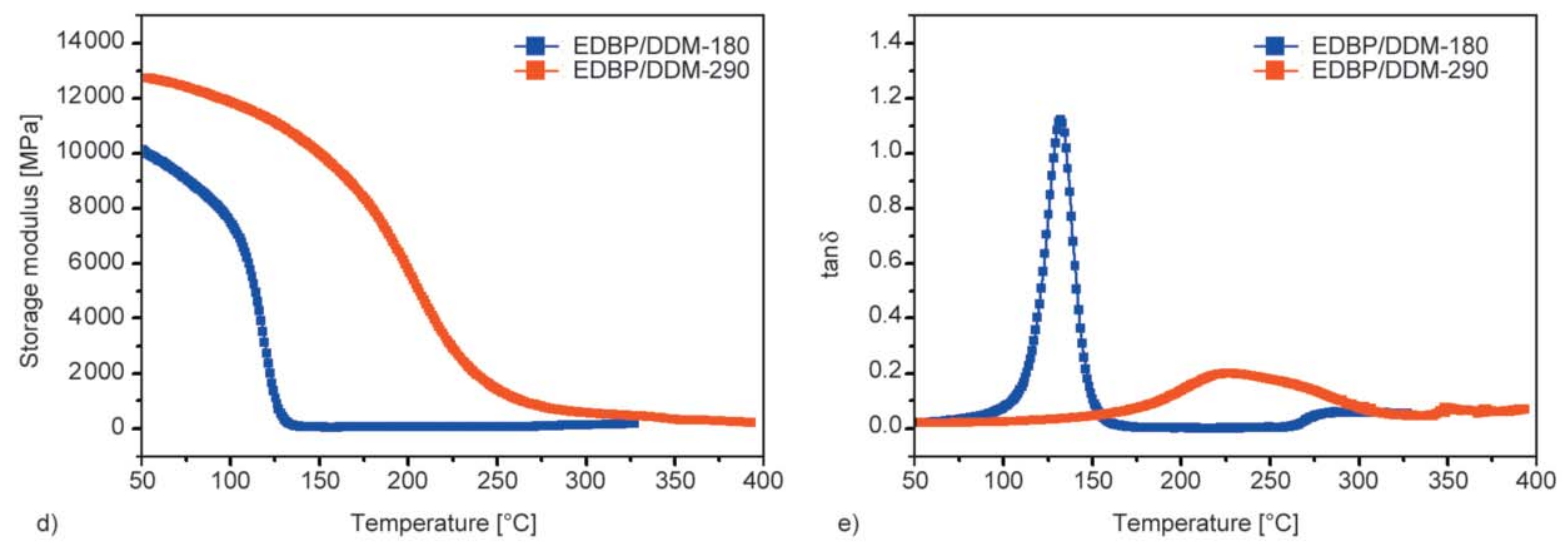

Figure 7. Thermomechanical properties of the cured resins. a) DMA spectra for the storage modulus and b) tan $\delta$ against temperature of DGEBA/DDM and P-DBP-EP-n/DDM with different second curing procedure. c) the dashed red rectangle area in image (b) with higher magnification. d) DMA spectra for the storage modulus and e) $\tan \delta$ against temperature of EDBP/DDM.

where $n$ and $M$ represent the molarity and molar mass of the corresponding component in the epoxy formulations, respectively. Calculated $M_{\mathrm{c}}$ and results from DMA tests of the cured resins were summarized in Table 3. As shown in Figure 7b and Table 3, it can be clearly seen that P-DBP-EP-n/DDM-180 exhibited a $M_{\mathrm{c}}$ of 1488 , with a corresponding $T_{\mathrm{g}}$ of 102 , $65^{\circ} \mathrm{C}$ lower than that of DGEBA/DDM $\left(M_{\mathrm{c}}=982\right)$, indicating that a much lower crosslinked polymer network was obtained. Lower crosslinking density
Table 3. Comparison of properties from DMA testing for cured resins.

\begin{tabular}{|l|c|c|}
\hline & $\begin{array}{c}\boldsymbol{T}_{\mathbf{g}}{ }^{*} \\
{\left[{ }^{\circ} \mathbf{C}\right]}\end{array}$ & $\boldsymbol{M}_{\mathbf{c}}$ \\
\hline DGEBA/DDM & 167 & 982 \\
\hline P-DBP-EP-n/DDM-180 & 102 & 1488 \\
\hline P-DBP-EP-n/DDM-280 & 213 & 644 \\
\hline P-DBP-EP-n/DDM-300 & 263 & 236 \\
\hline P-DBP-EP-n/DDM-320 & 304 & 217 \\
\hline
\end{tabular}

${ }^{*} T_{\mathrm{g}}$ : Glass transition temperature define by the peak value temperature of $\tan \delta$ against temperature curve. 
and abundant allyl groups in P-DBP-EP-n/DDM-180 provided the biphenyl backbone with free volume and increased chain mobility, which was responsible for lower $T_{\mathrm{g}}$ value compared with DGEBA/DDM. However, it is noteworthy that $T_{\mathrm{g}}$ value is enhanced with increasing second-curing temperature accounting for increasing crosslinking density (decreasing $M_{\mathrm{c}}$ ). Interestingly, P-DBP-EP-n/DDM-320 exhibited an extremely low $M_{\mathrm{c}}$ of 217 and corresponding high $T_{\mathrm{g}}$ value of $304{ }^{\circ} \mathrm{C}$, with an $82 \%$ improvement compared with DGEBA/DDM. Similarly, $T_{\mathrm{g}}$ value of EDBP/ DDM increased from 132 to $226^{\circ} \mathrm{C}$ after the second curing process (Figure 7e). Such a high $T_{\mathrm{g}}$ value was attributed to the distinguished cured network as discussed in the section Curing network of P-DBP-EP$\mathrm{n} / \mathrm{DDM}$. On the one hand, a highly crosslinked network where polymer chains were 'frozen' by extra crosslinking sites of allyl groups resulted in low free volume and hindered the mobility of segments [40]. On the other hand, high crosslinking density aggravated rigidity and stiffness caused by numerous biphenyl structures, rendering cured network able to resist heat and deformation.

\subsection{Mechanical properties of P-DBP-EP-n/DDM}

Figure 8 and Table 4 show the tensile and notched impact properties of P-DBP-EP-n/DDM, EDBP/DDM, and DGEBA/DDM for comparison. P-DBP-EP/ DDM-180 and EDBP/DDM-180 showed lower tensile strength (42.9 and $44.5 \mathrm{MPa})$ than that of DGEBA/DDM (69.6 MPa). After the second curing process, the tensile strength of P-DBP-EP/DDM-320 and EDBP/DDM-290 reduced vastly to 20.7 and 19.4 MPa, with a decrease of 51.7 and $56.4 \%$, respectively. It was attributed to the high aromaticity of biphenyl structures which were more rigid than that of BPA, reducing chain mobility and weakening the ability to resist deformation. However, the higher stiffness originated from the rod-like rigid components made the molecular structure more stable, endowing P-DBP-EP-n/DDM-320 with a tensile modulus as high as DGEBA/DDM (2.0 GPa). The notched impact strength was tested to determine the toughness of materials, and as shown in Figure 8b, DGEBA/ DDM is a typical brittle material with a low notched impact strength of $3.6 \mathrm{~kJ} / \mathrm{m}^{2}$. As expected, EDBP/

Table 4. Tensile properties and notched impact strength for cured resins.

\begin{tabular}{|l|c|c|c|}
\hline & $\begin{array}{c}\text { Tensile strength } \\
{[\mathbf{M P a}]}\end{array}$ & $\begin{array}{c}\text { Tensile modulus } \\
{[\mathbf{G P a}]}\end{array}$ & $\begin{array}{c}\text { Notched impact strength } \\
{\left[\mathbf{k J} / \mathbf{m}^{2}\right]}\end{array}$ \\
\hline DGEBA/DDM & $69.6 \pm 1.2$ & $2.0 \pm 0.1$ & $3.6 \pm 0.7$ \\
\hline EDBP/DDM-180 & $44.5 \pm 1.1$ & $1.5 \pm 0.2$ & $2.1 \pm 0.7$ \\
\hline EDBP/DDM-290 & $19.4 \pm 1.7$ & $1.6 \pm 0.1$ & $2.0 \pm 0.6$ \\
\hline P-DBP-EP-n/DDM-180 & $42.9 \pm 4.0$ & $2.0 \pm 0.3$ & $1.9 \pm 0.3$ \\
\hline P-DBP-EP-n/DDM-320 & $20.7 \pm 2.1$ & $2.0 \pm 0.3$ & $2.5 \pm 0.4$ \\
\hline
\end{tabular}
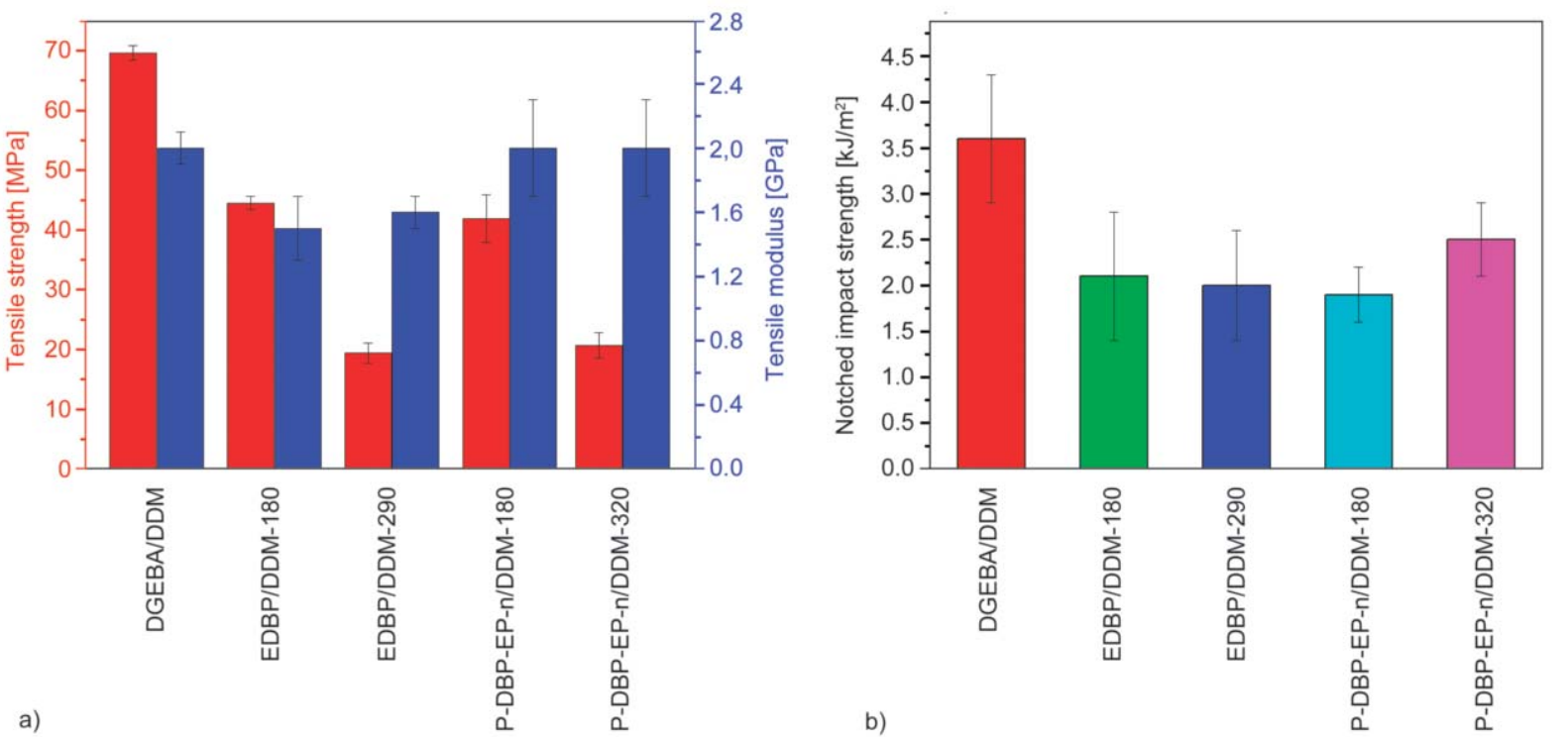

Figure 8. Mechanical properties of DGEBA/DDM, EDBP/DDM and P-DBP-EP-n. a) tensile and b) notched impact properties. 
DDM-180, EDBP/DDM-290, and P-DBP-EP-n/ DDM-180 containing multiple biphenyl aromatic structures exhibited high aromaticity and poor capacity for absorbing impact energy [41], resulting in corresponding lower impact strength, which is 41.6 , 44.4, and 47.2\% lower than that of DGEBA/DDM, respectively. Noticeably, P-DBP-EP-n/DDM-320 with the highest crosslinking density and aromaticity showed a slight increase of notched impact strength $\left(2.5 \mathrm{~kJ} / \mathrm{m}^{2}\right)$ compared with the EDBP/DDM-290. It was probably due to extra aliphatic segments between two biphenyl structures and flexible aliphatic chain caused by thermal addition polymerization of allyl units improved toughness for the cured resin.

\subsection{Thermal stability of P-DBP-EP-n/DDM}

The thermal stability of cured resins was investigated by TGA, and results are shown in Figure 9 and summarized in Table 5. Initial decomposition temperature, defined as the temperature at $5 \%$ weight loss $\left(T_{\mathrm{d} 5 \%}\right)$ is used to evaluate the thermal stability of the cured resins. As shown in Figure 9, DGEBA/DDM exhibited a one-stage decomposition with a $T_{\mathrm{d} 5 \%}$ of $371{ }^{\circ} \mathrm{C}$ and char yield of $17.5 \%$ at $700^{\circ} \mathrm{C}$. For P-DBP-EP-n/DDM-180, a two-stage decomposition was observed, with an earlier $T_{\mathrm{d} 5 \%}$ of $347^{\circ} \mathrm{C}$ compared with DGEBA/DDM. It might be assigned to the breakage of liable aliphatic allyl groups because less energy was needed compared with aromatic rings with unsaturated $\mathrm{C}=\mathrm{C}$ bonds $[42,43]$. However, it achieved a char residue of $28.6 \%$, with an increase of $11.1 \%$ in comparison with DGEBA/ DDM, suggesting that symmetric biphenyl structure reduced liable combustible gas [4], resisted pyrolysis [44, 45], and promoted charring. Contrary to DGEBA/DDM and P-DBP-EP-n/DDM-180, P-DBP-EP-n/DDM-320

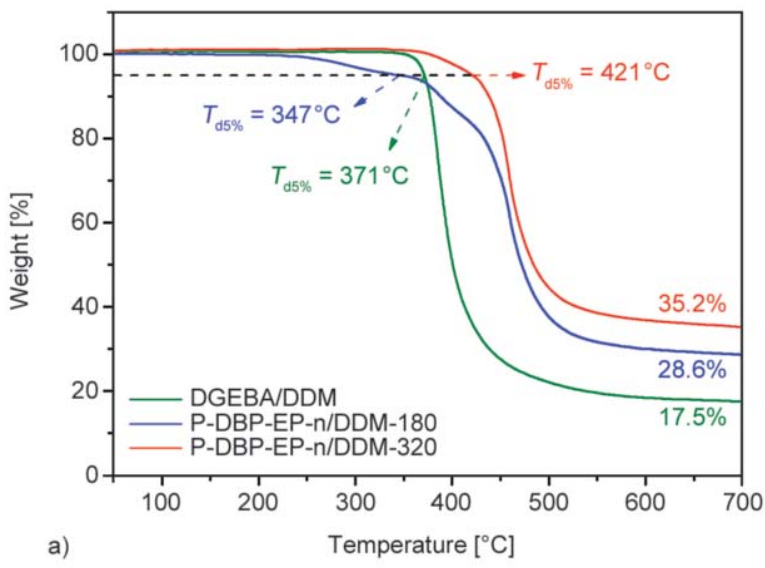

Figure 9. a) TGA and b) DTG curves of the cured resins.
Table 5. Comparison of properties from TGA testing for cured resins.

\begin{tabular}{|l|c|c|c|}
\hline & $\begin{array}{c}\boldsymbol{T}_{\mathbf{d} 5 \%} \\
{\left[{ }^{\circ} \mathbf{C}\right]}\end{array}$ & $\begin{array}{c}\boldsymbol{T}_{\max } \\
{\left[{ }^{\circ} \mathbf{C}\right]}\end{array}$ & $\begin{array}{c}\text { Char yield at } \mathbf{7 0 0}^{\circ} \mathbf{C} \\
{[\%]}\end{array}$ \\
\hline DGEBA/DDM & 371 & 384 & 17.5 \\
\hline P-DBP-EP-n/DDM-180 & 347 & 460 & 28.6 \\
\hline P-DBP-EP-n/DDM-280 & 396 & 460 & 32.1 \\
\hline P-DBP-EP-n/DDM-300 & 409 & 457 & 33.2 \\
\hline P-DBP-EP-n/DDM-320 & 421 & 458 & 35.2 \\
\hline
\end{tabular}

yielded the highest $T_{\mathrm{d} 5 \%}$ of $421{ }^{\circ} \mathrm{C}$ and char residue of $35.2 \%$, with an improvement of 13.5 and $101.1 \%$ compared with that of DGEBA/DDM, respectively. It is well known that thermal stability is not only affected by molecular structure but also by crosslink density. As discussed in the Thermomechanical properties of cured P-DBP-EP-n/DDM section, PDBP-EP-n/DDM-320 yielded the highest crosslinking density $\left(M_{\mathrm{c}}=217\right)$. The improvement of crosslinking density arising from the thermal addition polymerization of allyl units $[35,42]$ contributed to the heat resistance of the cured resins. With higher aromaticity and extra crosslinking density, segments motion was restricted [46], rendering a more stable and perfect crosslinked network and thereby obtaining outstanding thermal stability.

\subsection{Flame retardancy and morphology of char residue of P-DBP-EP-n/DDM}

High char residue is a good indication of flame-retardant performances of the materials and confirms our prediction; LOI and the UL 94 were carried out to investigate the flame retardancy of P-DBP-EP-n/ DDM, and results are summarized in Table 6. DGEBA/DDM exhibited an LOI value of $25.5 \%$ due to the combustible flexible aliphatic chain. Similarity, P-DBP-EP-n/DDM-180 with abundant allyl groups,

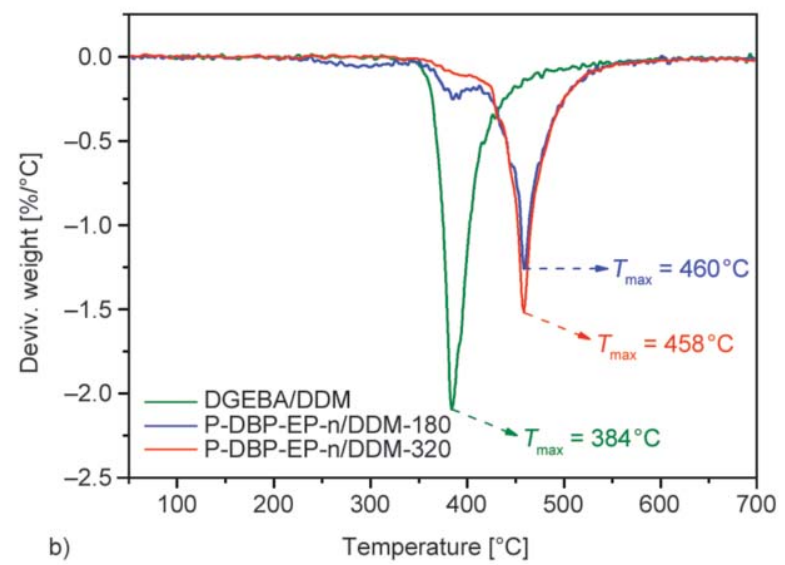


Table 6. Flame retardancy properties of cured resins.

\begin{tabular}{|l|c|c|}
\hline & LOI\% & UL94 \\
\hline DGEBA/DDM & 25.5 & NR \\
\hline P-DBP-EP-n/DDM-180 & 26.5 & NR \\
\hline P-DBP-EP-n/DDM-320 & 47.7 & V-0 \\
\hline
\end{tabular}

showed a slight increased LOI value of $26.5 \%$. In contrast, P-DBP-EP-n/DDM-320 behaved differently, with an extremely high LOI value of $47.7 \%$, which was approximately twice as much as DGEBA/DDM. It implied that P-DP-EP-n/DDM-320 is a nonflammable material in air [22] that has the potential to be used in cutting edge where high flame retardancy is required. The large margin increase of LOI value was ascribed to the highly crosslinked network resulting from extra crosslinking sites of allyl units and the compact biphenyl structure. A much higher crosslinked polymer network was obtained through thermal addition polymerization of allyl units. Polymer segments were wrapped tightly to form a stable and regular structure by the second cured network, restricting chain motion and thereby increasing structure stability as illustrated in Figure 5b. Moreover, higher aromaticity originated from multiple symmetrical biphenyl moieties endowed the cured resins with better heat resistance and ability of charring promotion, as stated above.

To further investigate the burning behavior of different cured resins, the UL 94 was performed, and the representative moments of the burning process were captured, as shown in Figure 10. As shown in Figure 10a, DGEBA/DDM was ignited quickly and burned vigorously with rapid flame propagation, and some melt dripping occurred owing to the gaseous combustible segment (Figure $10 \mathrm{a}_{6}$ ). Such a flourishing combustible failed to pass the $\mathrm{V}$ rating, and therefore just a little char residue was left, as shown in Figure 11. For P-DBP-EP-n/DDM-180, it burned more fiercely because it contained more aliphatic segments compared with DGEBA/DDM and was qualified for no rating as well. However, there was no melt dripping for the entire combustion, predicting that the

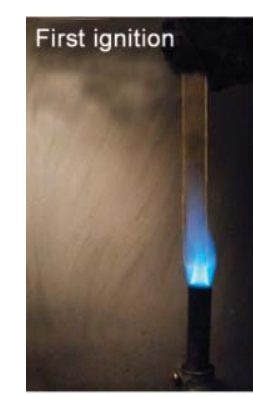

$\left.a_{1}\right)$

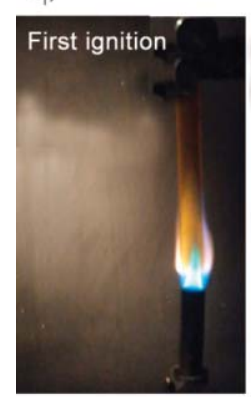

$\left.b_{1}\right)$

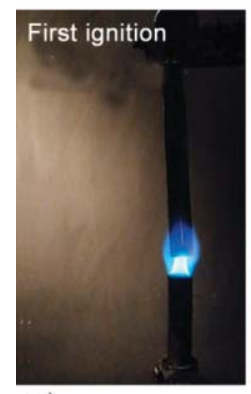

$\left.c_{1}\right)$

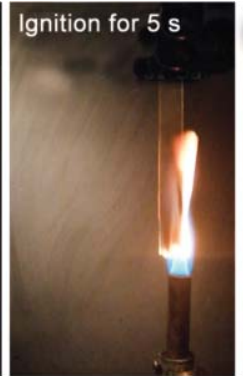

$\left.a_{2}\right)$

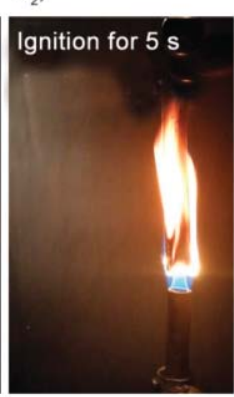

$\left.b_{2}\right)$

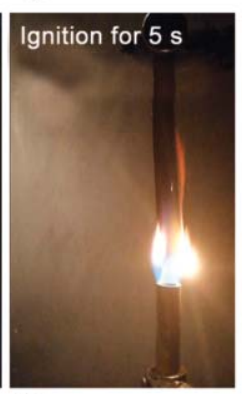

$c_{2}$ )

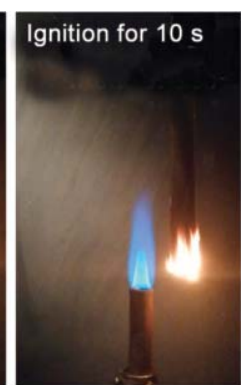

$\left.a_{3}\right)$

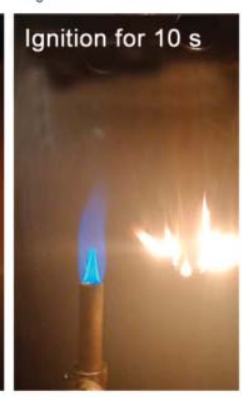

$b_{3}$ )

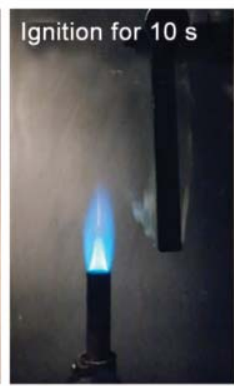

$\mathrm{c}_{3}$ )

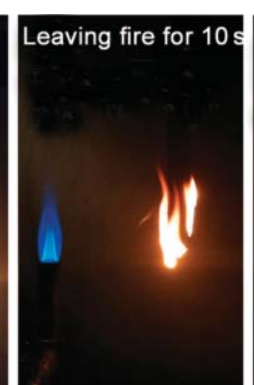

$a_{4}$ )

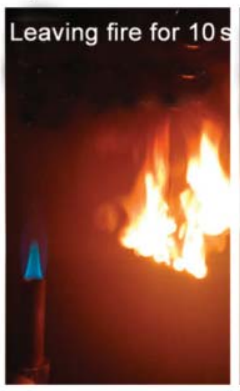

$b_{4}$ )

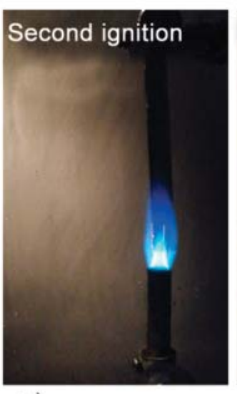

C)

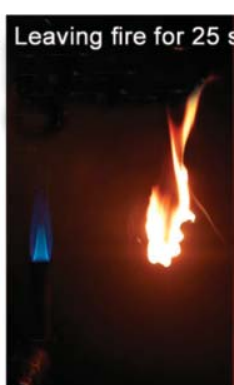

$a_{5}$ )

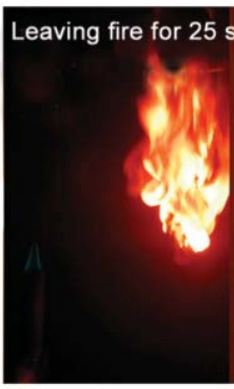

$b_{5}$ )

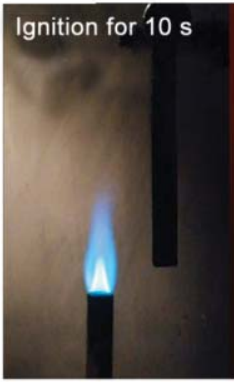

C.

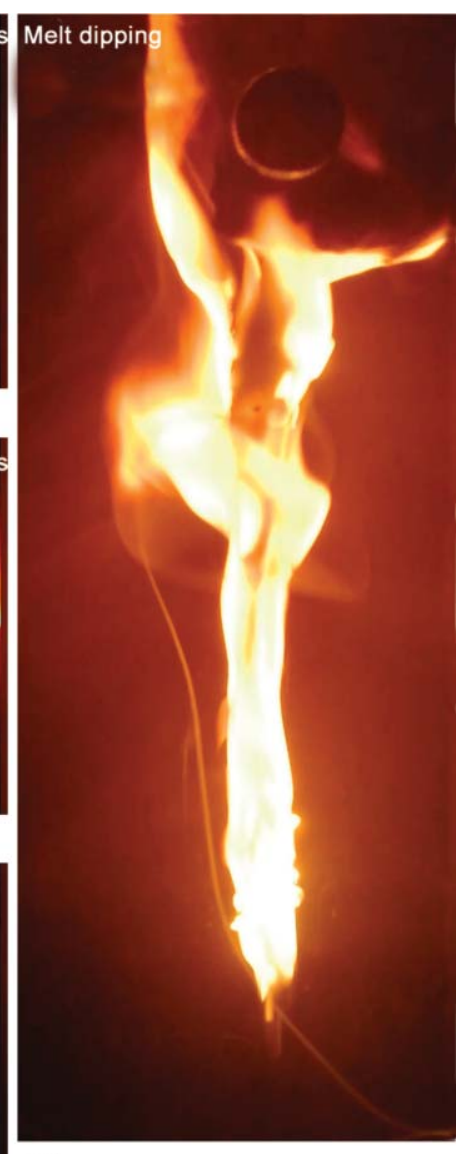

$a_{6}$ )

Figure 10. Video screenshots of UL94 test at representative time. a) DGEBA/DDM, b) P-DBP-EP-n/DDM-180, c) P-DBPEP-n/DDM-320. 


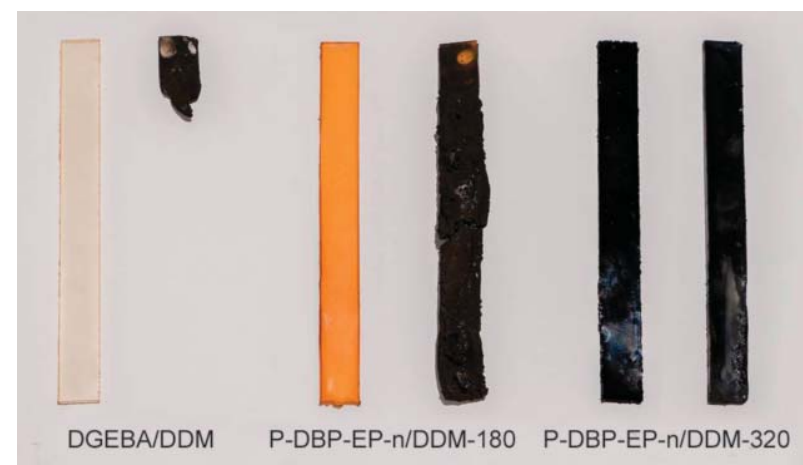

Figure 11. Digital photos taken from the residual char for DGEBA/DDM, P-DBP-EP-n/DDM-180 and P-DBP-EP-n/DDM-320.

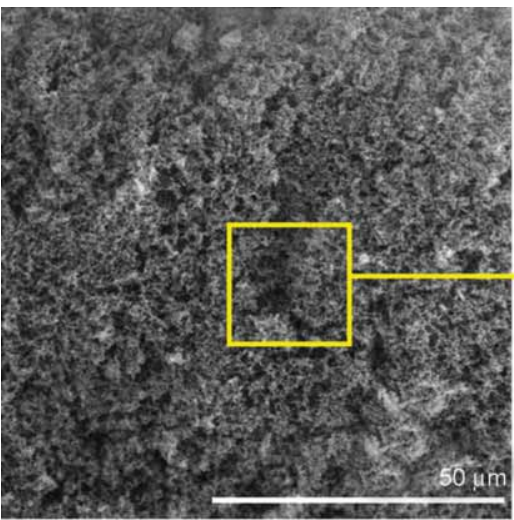

$\left.a_{1}\right)$

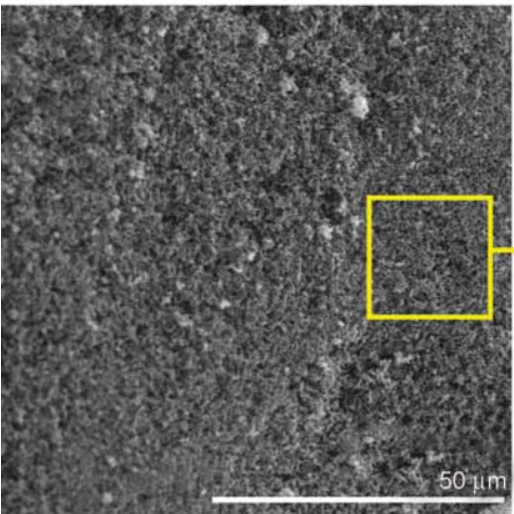

$\left.b_{1}\right)$

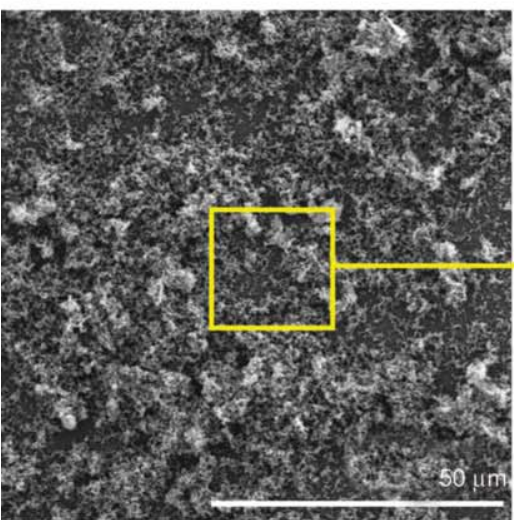

$c_{1}$ )

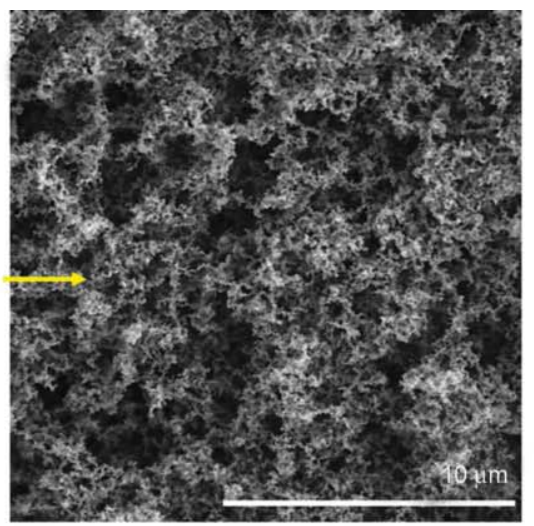

$\left.a_{2}\right)$

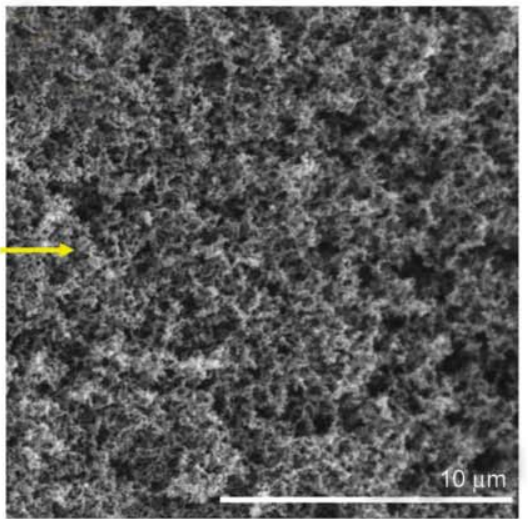

$b_{2}$ )

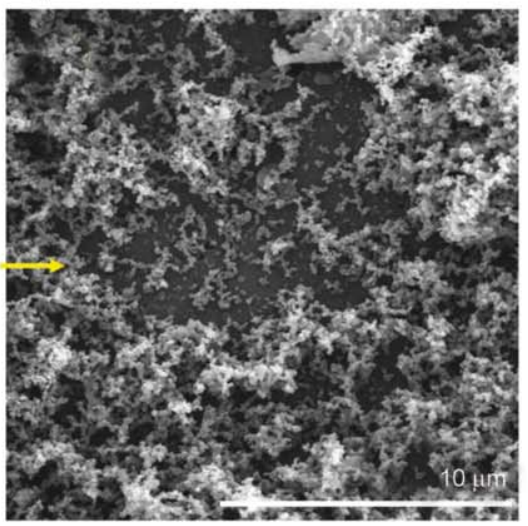

$\mathrm{c}_{2}$ ) structural stability and complete char residue as protective layer were assigned to it [47] as displayed in Figure 11. Conversely, P-DBP-EP-n/DDM-320 selfextinguished within about $5 \mathrm{~s}$, and then a second ignition (Figure 10c $\mathrm{c}_{4}$ ) was applied immediately, but it behaved in the same way, passing the $\mathrm{V}-0$ rating. As shown in Figure 11, P-DBP-EP-n/DDM-320 was kept intact, and only the bottom where it was exposed to fire was burned and carbonized after the test. It is indicative that the highly crosslinked network and stable biphenyl structures of P-DBP-EP-n contribute to the outstanding flame-retardant properties.

Figure 12. SEM images taken from the residual char collected from UL94 tests for DGEBA/DDM (a), P-DBP-EP-n/DDM180 (b) and P-DBP-EP-n/DDM (c) (Outer layer 1,2 and inner layer 3.). 
As for the distinct burning behaviors for different cured resins, SEM was carried out to investigate the morphologies of the residual char collected from the UL94, and the SEM images for different samples are shown in Figure 12. For DGEBA/DDM (Figure 12a), it was found that residual char was loose and porous, letting heat and oxygen penetrate the inner matrix through numerous holes [48]. Meanwhile, the combustible aliphatic fracture was easily exposed to heat through these broken holes (Figure 12 $\mathrm{a}_{3}$ ), leading to melting drop and combustion acceleration [24]. In contrast, P-DBP-EP-n/DDM-180 (Figure 12b) yielded denser and more compact and continuous residual char, which was beneficial for flame retardancy in theory $[49,50]$. Such a complete and continuous char layer could retard the exchange of heat and low molecular fragments, obtaining complete char residue (Figure 11). It is indicative that P-DBP-EP-n/DDM has the potential to exhibit more excellent flame retardancy with further suitable curing procedures. As speculated, the morphology of char residue of P-DBP-EP-n/DDM-320 was vastly distinct from the former samples. As shown in Figure 12c, the outer layer char residue seemed loose and discontinuous, whereas the underlying matrix was smooth. It could be found that only the surface exposed to fire was carbonized and the matrix was well protected. Dense and compact holes were observed in the inner layer, suggesting fewer combustible fragments released owing to the stable aromatic structure and highly crosslinked network. Furthermore, the combustible gas was enveloped by the continuous matrix, blocking the spread of combustion effectively. All the results above indicate that P-DBP-EP-n/DDM-320 exhibits satisfactory flame-retardant effects.

\section{Conclusions}

In the current study, we successfully synthesized an epoxy oligomer derived from biomass magnolol through one-step glycidylation. The chemical structure of P-DBP-EP-n was systematically characterized by ${ }^{1} \mathrm{H}$ NMR, ${ }^{13} \mathrm{C}$ NMR, and MALDI-TOF. The oligomer P-DBP-EP-n was a mixture with different polymerization degrees where $n=1$ came to prominence. The viscosity of P-DBP-EP-n was $11.7 \mathrm{~Pa} \cdot \mathrm{s}$, which was slightly lower than that of DGEBA, exhibiting excellent processability at room temperature. Then the cured P-DBP-EP-n was prepared with curing agent DDM and following thermal addition polymerization of allyl units at a higher temperature. FTIR was carried out to determine the extent of reaction, and an $8 \mathrm{~h}$-second-curing process at $320^{\circ} \mathrm{C}$ was considered as optimum. The tensile and notched impact tests showed that P-DBP-EP-n/DDM-320 could not compete with DGEBA/DDM and even EDBP/DDM due to the highly crosslinked aromatic network with weak segments mobility. However, P-DBP-EP-n/DDM-320 exhibited an extremely high $T_{\mathrm{g}}$ value of $304^{\circ} \mathrm{C}$, which increased by $82 \%$ compared with that of DGEBA/DDM owing to higher crosslinking density $\left(M_{\mathrm{c}}=217\right)$. In terms of thermal stability, $T_{\mathrm{d} 5 \%}$ increased to $421^{\circ} \mathrm{C}$ with a residual mass of $35.2 \%$ at $700{ }^{\circ} \mathrm{C}$ owing to the introduction of rigid biphenyl structures, which promoted charring. Furthermore, P-DBP-EP-n/DDM-320 was nonflammable, passing V-0 rating for the UL 94 test and achieving an $80 \%$ increase of LOI value (47.7 to $23.5 \%$ ). This distinguished flame retardancy was ascribed to more dense morphology of char residue, which prevented heat and oxygen from penetrating the inner matrix. In conclusion, the magnolol-based oligomer is found as a renewable and promising substitute for DGEBA toward heat resistance and flame retardancy, satisfying the high application requirements.

\section{Acknowledgements}

This work was financially supported by the National Nature Science Foundation of China (No. 52073065), Guangdong Province Research and Development Plan of Key Areas (No.2019B010929001), Guangzhou Science and Technology Plan Project (No. 20180410326) and the Guangzhou Emerging Industry Development Fund Project of the Guangzhou Development and Reform Commission.

\section{References}

[1] Auvergne R., Caillol S., David G., Boutevin B., Pascault J-P.: Biobased thermosetting epoxy: Present and future. Chemical Reviews, 114, 1082-1115 (2014).

https://doi.org/10.1021/cr3001274

[2] Vandenberg L. N., Hauser R., Marcus M., Olea N., Welshons W. V.: Human exposure to bisphenol A(BPA). Reproductive Toxicology, 24, 139-177 (2007). https://doi.org/10.1016/j.reprotox.2007.07.010

[3] Wan J., Zhao J., Zhang X., Fan H., Zhang J., Hu D., Jin P., Wang D-Y.: Epoxy thermosets and materials derived from bio-based monomeric phenols: Transformations and performances. Progress in Polymer Science, 108, 101287/1-101287/46 (2020).

https://doi.org/10.1016/j.progpolymsci.2020.101287 
[4] Wan J., Zhao J., Gan B., Li C. Molina-Aldareguia J., Zhao Y., Pan Y-T., Wang D-Y.: Ultrastiff biobased epoxy resin with high Tg and low permittivity: From synthesis to properties. ACS Sustainable Chemistry and Engineering, 4, 2869-2880 (2016).

https://doi.org/10.1021/acssuschemeng.6b00479

[5] Liu J., Wang S., Peng Y., Zhu J., Zhao W., Liu X.: Advances in sustainable thermosetting resins: From renewable feedstock to high performance and recyclability. Progress in Polymer Science, 113, 101353/1-101353/49 (2021). https://doi.org/10.1016/j.progpolymsci.2020.101353

[6] Ma S., Liu X., Jiang Y., Tang Z., Zhang C., Zhu J.: Biobased epoxy resin from itaconic acid and its thermosets cured with anhydride and comonomers. Green Chemistry, 15, 245-254 (2013). https://doi.org/10.1039/C2GC36715G

[7] Deng J., Liu X., Li C., Jiang Y., Zhu J.: Synthesis and properties of a bio-based epoxy resin from 2,5-furandicarboxylic acid (FDCA). RSC Advances, 5, 15930 15939 (2015). https://doi.org/10.1039/c5ra00242g

[8] Fu L., Yang L., Dai C., Zhao C., Ma L.: Thermal and mechanical properties of acrylated expoxidized-soybean oil-based thermosets. Journal of Applied Polymer Science, 117, 2220-2225 (2010). https://doi.org/10.1002/app.32126

[9] Jia P., Ma Y., Xia H., Zheng M., Feng G., Hu L., Zhang M., Zhou Y.: Clean synthesis of epoxidized tung oil derivatives via phase transfer catalyst and thiol-ene reaction: A detailed study. ACS Sustainable Chemistry and Engineering, 6, 13983-13994 (2018).

https://doi.org/10.1021/acssuschemeng.8b02446

[10] Lalitha K., Sandeep M., Prasad Y. S., Sridharan V., Maheswari C. U., Srinandan C. S., Nagarajan S.: Intrinsic hydrophobic antibacterial thin film from renewable resources: Application in the development of anti-biofilm urinary catheters. ACS Sustainable Chemistry and Engineering, 5, 436-449 (2016). https://doi.org/10.1021/acssuschemeng.6b01806

[11] Liu Z., Chen J., Knothe G., Nie X., Jiang J.: Synthesis of epoxidized cardanol and its antioxidative properties for vegetable oils and biodiesel. ACS Sustainable Chemistry and Engineering, 4, 901-906 (2017). https://doi.org/10.1021/acssuschemeng.5b00991

[12] Chen J., Nie X., Liu Z., Mi Z., Zhou Y.: Synthesis and application of polyepoxide cardanol glycidyl ether as biobased polyepoxide reactive diluent for epoxy resin. ACS Sustainable Chemistry and Engineering, 3, 1164 1171 (2017). https://doi.org/10.1021/acssuschemeng.5b00095

[13] Ma S., Liu X., Fan L., Jiang Y., Cao L., Tang Z., Zhu J.: Synthesis and properties of a bio-based epoxy resin with high epoxy value and low viscosity. ChemSusChem, 7, 555-562 (2014).

https://doi.org/10.1002/cssc.201300749
[14] Kim J. R., Sharma S.: The development and comparison of bio-thermoset plastics from epoxidized plant oils. Industrial Crops and Products, 36, 485-499 (2012). https://doi.org/10.1016/j.indcrop.2011.10.036

[15] Sahoo S. K., Khandelwal V., Manik G.: Development of toughened bio-based epoxy with epoxidized linseed oil as reactive diluent and cured with bio-renewable crosslinker. Polymer Advanced Technologies, 29, 565574 (2017).

https://doi.org/10.1002/pat.4166

[16] Sahoo S. K., Mohanty S., Nayak S. K.: Synthesis and characterization of bio-based epoxy blends from renewable resource based epoxidized soybean oil as reactive diluent. Chinese Journal of Polymer Science, 33, 137152 (2015).

https://doi.org/10.1007/s10118-015-1568-4

[17] Kumar S., Samal S. K., Mohanty S., Nayak S. K.: Recent development of biobased epoxy resins: A review. Polymer-Plastics Technology and Engineering, 57, 133-155 (2018). https://doi.org/10.1080/03602559.2016.1253742

[18] Dai J., Teng N., Liu J., Feng J., Zhu J., Liu X.: Synthesis of bio-based fire-resistant epoxy without addition of flame retardant elements. Composites Part B, 179, 107523/1-107523/10 (2019).

https://doi.org/10.1016/j.compositesb.2019.107523

[19] Fang Z., Weisenberger M. C., Meier M. S.: Utilization of lignin-derived small molecules: Epoxy polymers from lignin oxidation products. ACS Applied Bio Materials, 3, 881-890 (2020).

https://doi.org/10.1021/acsabm.9b00954

[20] Fache M., Darroman E., Besse V., Auvergne R., Caillol S., Boutevin B.: Vanillin, a promising biobased building-block for monomer synthesis. Green Chemistry, 16, 1987-1998 (2014). https://doi.org/10.1039/c3gc42613k

[21] Liu J., Dai J., Wang S., Peng Y., Cao L., Liu X.: Facile synthesis of bio-based reactive flame retardant from vanillin and guaiacol for epoxy resin. Composites Part B, 190, 107926/1-107926/13 (2020). https://doi.org/10.1016/j.compositesb.2020.107926

[22] Wan J., Gan B., Li C., Molina-Aldareguia J., Li Z., Wang X., Wang D-Y.: A novel biobased epoxy resin with high mechanical stiffness and low flammability: Synthesis, characterization and properties. Journal of Materials Chemistry A, 3, 21907-21921 (2015). https://doi.org/10.1039/c5ta02939b

[23] Wan J., Gan B., Li C., Molina-Aldareguia J., Kalali E. N., Wang X., Wang D-Y.: A sustainable, eugenol-derived epoxy resin with high biobased content, modulus, hardness and low flammability: Synthesis, curing kinetics and structure-property relationship. Chemical Engineering Journal, 284, 1080-1093 (2016). https://doi.org/10.1016/j.cej.2015.09.031 
[24] Tian Y., Wang Q., Shen L., Cui Z., Kou L., Cheng J., Zhang J.: A renewable resveratrol-based epoxy resin with high $T_{\mathrm{g}}$, excellent mechanical properties and low flammability. Chemical Engineering Journal, 383, 123124/1-123124/9 (2016).

https://doi.org/10.1016/j.cej.2019.123124

[25] Lee Y-J., Lee Y. M., Lee C-K., Jung J. K., Han S. B., Hong J. T.: Therapeutic applications of compounds in the magnolia family. Pharmacology and Therapeutics, 130, 157-176 (2011).

https://doi.org/10.1016/j.pharmthera.2011.01.010

[26] Wacker K. T., Weems A. C., Lim S-M., Khan S., Felder S. E., Dove A. P., Wooley K. L.: Harnessing the chemical diversity of the natural product magnolol for the synthesis of renewable, degradable neolignan thermosets with tunable thermomechanical characteristics and antioxidant activity. Biomacromolecules, 20, 109 117 (2019).

https://doi.org/10.1021/acs.biomac.8b00771

[27] Teng N., Yang S., Dai J., Wang S., Zhao J., Zhu J., Liu $\mathrm{X}$.: Making benzoxazine greener and stronger: Renewable resource, microwave irradiation, green solvent, and excellent thermal properties. ACS Sustainable Chemistry and Engineering, 7, 8715-8723 (2019).

https://doi.org/10.1021/acssuschemeng.9b00607

[28] Xu S., Han Y., Guo Y., Luo Z., Ye L., Li Z., Zhou H., Zhao Y., Zhao T.: Allyl phenolic-phthalonitrile resins with tunable properties: Curing, processability and thermal stability. European Polymer Journal, 95, 394-405 (2017).

https://doi.org/10.1016/j.eurpolymj.2017.08.010

[29] Iredale R. J., Ward C., Hamerton I.: Modern advances in bismaleimide resin technology: A $21^{\text {st }}$ century perspective on the chemistry of addition polyimides. Progress in Polymer Science, 69, 1-21 (2017). https://doi.org/10.1016/j.progpolymsci.2016.12.002

[30] van Krevelen D. W.: Some basic aspects of flame resistance of polymeric materials. Polymer, 16, 615-620 (1975). https://doi.org/10.1016/0032-3861(75)90157-3

[31] Qi Y., Weng Z., Zhang K., Wang J., Zhang S., Liu C., Jian X.: Magnolol-based bio-epoxy resin with acceptable glass transition temperature, processability and flame retardancy. Chemical Engineering Jouranl, 387, 124115/1-124115/14 (2020). https://doi.org/10.1016/j.cej.2020.124115

[32] Fache M., Viola A., Auvergne R., Boutevin B., Caillol S.: Biobased epoxy thermosets from vanillin-derived oligomers. European Polymer Journal, 68, 526-535 (2015). https://doi.org/10.1016/j.eurpolymj.2015.03.048

[33] Shang L., Zhang X., Zhang M., Jin L., Liu L., Xiao L., Li M., Ao Y.: A highly active bio-based epoxy resin with multi-functional group: Synthesis, characterization, curing and properties. Journal of Materials Science, 53, 5402-5417 (2018). https://doi.org/10.1007/s10853-017-1797-8
[34] Amarasekara A. S., Garcia-Obergon R., Thompson A. K.: Vanillin-based polymers: IV. Hydrovanilloin epoxy resins. Journal of Applied Polymer Science, 136, 47000/1-47000/6 (2019). https://doi.org/10.1002/app.47000

[35] Kumar K. S. S., Nair C. P. R., Radhakrishnan T. S., Ninan K. N.: Bis allyl benzoxazine: Synthesis, polymerisation and polymer properties. European Polymer Journal, 43, 2504-2514 (2007).

https://doi.org/10.1016/j.eurpolymj.2007.03.028

[36] Miao J-T., Yuan L., Guan Q., Liang G., Gu A.: Biobased heat resistant epoxy resin with extremely high biomass content from 2,5-furandicarboxylic acid and eugenol. ACS Sustainable Chemistry and Engineering, 5, 7003-7011 (2017). https://doi.org/10.1021/acssuschemeng.7b01222

[37] Wang S., Ma S., Xu C., Liu Y., Dai J., Wang Z., Liu X., Chen J., Shen X., Wei J., Zhu J.: Vanillin-derived highperformance flame retardant epoxy resins: Facile synthesis and properties. Macromolecules, 50, 1892-1901 (2017). https://doi.org/10.1021/acs.macromol.7b00097

[38] Ma S., Webster D., Jabeen F.: Hard and flexible, degradable thermosets from renewable bioresources with the assistance of water and ethanol. Macromolecules, 49, 3780-3788 (2016). https://doi.org/10.1021/acs.macromol.6b00594

[39] Xie T., Rousseau I. A.: Facile tailoring of thermal transition temperatures of epoxy shape memory polymers. Polymer, 50, 1852-1856 (2009).

https://doi.org/10.1016/j.polymer.2009.02.035

[40] Savonnet E., Grau E., Grelier S., Defoort B., Cramail H.: Divanillin-based epoxy precursors as DGEBA substitutes for biobased epoxy thermosets. ACS Sustainable Chemistry and Engineering, 6, 11008-11017 (2018). https://doi.org/10.1021/acssuschemeng.8b02419

[41] Kumar S., Krishnan S., Samal S. K., Mohanty S., Nayak S. K.: Toughening of petroleum based (DGEBA) epoxy resins with various renewable resources based flexible chains for high performance applications: A review. Industrial and Engineering Chemistry Research, 57, 27112726 (2018).

https://doi.org/10.1021/acs.iecr.7b04495

[42] Chen W-C., Kuo S-W.: Ortho-imide and allyl groups effect on highly thermally stable polybenzoxazine/double-decker-shaped polyhedral silsesquioxane hybrids. Macromolecules, 51, 9602-9612 (2018).

https://doi.org/10.1021/acs.macromol.8b02207

[43] Mora A-S., Tayouo R., Boutevin B., David G., Caillol S.: Vanillin-derived amines for bio-based thermosets. Green Chemistry, 20, 4075-4084 (2018). https://doi.org/10.1039/C8GC02006J

[44] Masatoshi I., Kiuchi Y.: Self-extinguishing epoxy molding compound with no flame-retarding additives for electronic components. Journal of Materials Science: Materials Electronics, 12, 715-723 (2001). https://doi.org/10.1023/A:1012940826406 
[45] Song T., Li Z., Liu J., Yang S.: Synthesis, characterization and properties of novel crystalline epoxy resin with good melt flowability and flame retardancy based on an asymmetrical biphenyl unit. Polymer Science Series B, 55, 147-157 (2013).

https://doi.org/10.1134/S156009041303007X

[46] Zuo C., Han J., Si Z., Xue G.: Synthesis, characterization, and properties of a novel epoxy resin containing both binaphthyl and biphenyl moieties. Journal of Applied Polymer Science, 114, 3889-3895 (2009).

https://doi.org/10.1002/app.29752

[47] Sun J., Yu Z., Wang X., Wu D.: Synthesis and performance of cyclomatrix polyphosphazene derived from trispiro-cyclotriphosphazene as a halogen-free nonflammable material. ACS Sustainable Chemistry and Engineering, 2, 231-238 (2014).

https://doi.org/10.1021/sc400283d
[48] Wang X., Kalali E. N., Wang D-Y.: Renewable cardanol-based surfactant modified layered double hydroxide as a flame retardant for epoxy resin. ACS Sustainable Chemistry and Engineering, 3, 3281-3290 (2015).

https://doi.org/10.1021/acssuschemeng.5b00871

[49] Xu Y-J., Wang J., Tan Y., Qi M., Chen L., Wang Y-Z.: A novel and feasible approach for one-pack flame-retardant epoxy resin with long pot life and fast curing. Chemical Engineering Journal, 337, 30-39 (2018). https://doi.org/10.1016/j.cej.2017.12.086

[50] Shi Y-Q., Fu T., Xu Y-J., Li D-F., Wang X-L., Wang YZ.: Novel phosphorus-containing halogen-free ionic liquid toward fire safety epoxy resin with well-balanced comprehensive performance. Chemical Engineering Journal, 354, 208-219 (2018).

https://doi.org/10.1016/j.cej.2018.08.023 